\title{
La mirada estudiantil acerca del proceso de práctica supervisada en las carreras de Pedagogía de la Universidad Nacional'
}

\author{
Student Point of View on the Supervised Practice that is part of the Pedagogy Study \\ Programs of Universidad Nacional, Costa Rica
}

\author{
Maureen Camacho-Oviedo² \\ Universidad Nacional \\ Centro de Investigación y Docencia en Educación \\ Heredia, Costa Rica \\ maureen.camacho.oviedo@una.cr \\ Rocío Castillo-Cedeño3 \\ Universidad Nacional \\ Centro de Investigación y Docencia en Educación \\ Heredia, Costa Rica \\ rociocastillocedeno@gmail.com
}

\begin{abstract}
${ }^{1}$ Las figuras $1,2,3,4,5,6,7,8,9,10$ y 14 son propiedad del co-autor Luis Alfredo Miranda-Calderón, quien autorizó su uso para este artículo.

${ }^{2}$ Máster en Educación con énfasis en Docencia Universitaria, de la Universidad Nacional, Costa Rica. Licenciada en Ciencias de la Educación con concentración en Educación Básica I y II Ciclos. Actualmente, es subdirectora de la División de Educación Básica (DEB) del Centro de Investigación y Docencia en Educación (CIDE) de la Universidad Nacional (UNA) y responsable del Programa de Desarrollo Académico y Gestión Organizacional de la División de Educación Básica. Como académica de la DEB, en la Carrera de Pedagogía con énfasis en I y ll Ciclos de la Educación General Básica; se ha desempeñado en el área de docencia, en procesos de intervención pedagógica a nivel de diplomado y bachillerato, como proyectista y responsable de la Carrera de Pedagogía con énfasis en I y II Ciclos. Ha laborado como docente de primaria en centros educativos públicos y privados. Posee publicaciones en el campo de pedagogía y la didáctica.

${ }^{3}$ Doctora en Educación con mención en Mediación Pedagógica. Magíster en Administración Educativa y en Psicopedagogía. Profesora y bachiller en ciencias de la Educación con énfasis en Educación Preescolar, Universidad Nacional. Veintiún años de experiencia en el ámbito de la educación preescolar y la universitaria. Ha participado activamente en procesos de formación de formadores, principalmente, en el diseño e implementación de cursos de pedagogía a distancia, en la Universidad Estatal a Distancia. Durante cinco años se desempeñó como decana de la Facultad de Educación de la Universidad De La Salle Costa Rica y trabajó durante un año como Vicerrectora Académica en esta misma universidad. Actualmente, es docente e investigadora en el Centro de Investigación y Docencia en Educación de la Universidad Nacional de Costa Rica. Autora del libro: La conciencia cósmica en la primera infancia. Reflexiones paradigmáticas, propuestas biopedagógicas y un acercamiento a la espiritualidad de las niñas y los niños.
\end{abstract}


doi: http://dx.doi.org/10.15359/ree.19-2.23

URL: http://www.una.ac.cr/educare

CORREO: educare@una.cr

Heidy León-Arce
Universidad Nacional
Centro de Investigación y Docencia en Educación
Heredia, Costa Rica
heidy.leon.arce@una.cr
Luis Alfredo Miranda-Calderón
Universidad Nacional
Centro de Investigación y Docencia en Educación
Heredia, Costa Rica
alfremira@gmail.com
Zulay Pereira-Pérez
Universidad Nacional
Centro de Investigación y Docencia en Educación
Heredia, Costa Rica
zulay.pereira.perez@una.cr
Erika Vásquez-Salazar
Universidad Nacional
Centro de Investigación y Docencia en Educación
Heredia, Costa Rica
erika.vasquez.salazar@una.cr

${ }^{4}$ Máster en Pedagogía con énfasis en Diversidad de los Procesos Educativos, Licenciada en Educación Especial con énfasis en Integración, Universidad Nacional de Costa Rica. Educadora, académica e investigadora de la División de Educación Básica del Centro de Investigación y Docencia en Educación (CIDE) de la Universidad Nacional. Actualmente gestora de la Carrera de Educación Especial y participante del Programa Desarrollo Académico. Posee publicaciones en el campo de la pedagogía y la educación especial.

${ }^{5}$ Académico en la División de Educación Básica del Centro de Investigación y Docencia en Educación de la Universidad Nacional, Costa Rica. Magíster con especialidades en Administración Educativa, Universidad de Costa Rica y Formación de Formadores de Docentes de Educación Primaria, Universidad Nacional. Bachiller en Actuación y Dirección de las Artes Dramáticas y en Ciencias de la Educación en I y II Ciclos-UCR. Licenciado en Ciencias de la Educación en I y II ciclos con énfasis en Educación Rural. Como maestro rural unidocente ha implementado modelos de gestión participativa, y diversas investigaciones y exploraciones relacionadas con el aprendizaje mediado por el uso y aprovechamiento del entorno natural. Docente investigador en la Escuela Nueva Laboratorio Emma Gamboa de la Universidad de Costa Rica. Autor de diversos artículos relacionados con la pedagogía, el desarrollo de la capacidad creadora, educación en contextos rurales, arte en la mediación pedagógica e investigación. Ha liderado procesos de formación docente y capacitación a docentes de educación preescolar, primaria y secundaria. Ponente en congresos nacionales e internacionales.

${ }^{6}$ Doctora en Educación, de la Universidad Estatal a Distancia, Costa Rica. Catedrática de la Universidad Nacional, Costa Rica. Máster y Licenciada en Psicología, de la Universidad de Costa Rica. Adscrita al Colegio Profesional de Psicólogos de Costa Rica. Ex coordinadora del Programa de Investigación en Epistemología Genética y Educación del IIMEC, actualmente el Instituto de Investigación en Educación (INIE) de la Universidad de Costa Rica (UCR). Ex directora y docente de la División de Educación Básica del Centro de Investigación y Docencia en Educación de la Universidad Nacional, Costa Rica. Investigadora del Centro de Investigación y Docencia en Educación de la Universidad Nacional, Costa Rica. Tiene publicaciones en el campo de la psicología y la pedagogía.

${ }^{7}$ Académica en la División de Educación Básica del Centro de Investigación y Docencia en Educación de la Universidad Nacional, Costa Rica. Máster con especialidad en Pedagogía de la Universidad Nacional. Bachiller en Ciencias de la Educación I y II ciclo concentración Inglés de la Universidad Estatal a Distancia. Licenciada en Docencia de la Universidad Estatal a Distancia. Actualmente es gestora de la carrera de Enseñanza del Inglés para I y II Ciclos. Posee publicaciones en el campo de la pedagogía. 
REVISTA Electrónica EducAre (EDUCARE Electronic JOURNAL) EISSN: 1409-4258 VOl. 19(2) MAYO-AGOSTO, 2015: 429-465

doi: http://dx.doi.org/10.15359/ree.19-2.23

URL: http://www.una.ac.cr/educare

CORREO: educare@una.cr

Recibido 29 de octubre de 2014 • Corregido 10 de abril de 2015 • Aceptado 24 de abril de 2015

Resumen. El presente artículo emerge de una investigación acerca de las valoraciones sobre la práctica supervisada en las carreras de pedagogía (Camacho et al., 2014) por parte del profesorado, personal docente observador y estudiantes En este artículo, se enfatizan exclusivamente los datos desde la mirada estudiantil. Se contó con la participación del estudiantado que recién finalizaba el proceso de práctica supervisada a nivel de Diplomado en las carreras de Preescolar, I y ll ciclos y Enseñanza del Inglés y del nivel de Bachillerato en la carrera de Educación Especial. Se aplicó un cuestionario y se realizó un conversatorio en el que se analizó la práctica supervisada desde su perspectiva. Los principales hallazgos señalan la importancia del proceso, pero también recogen una serie de preocupaciones estudiantiles acerca de las necesidades que experimentan en cuanto a la formación para poder enfrentar, de manera más apropiada, la práctica supervisada y brindan sugerencias a las carreras en ese sentido.

Palabras claves. Pedagogía, estudiantes, formación, práctica supervisada, observadores y observadoras.

Abstract. This paper is a product of a research project conducted with the purpose of assessing the supervised practice that is part of the Pedagogy Study Programs (Camacho et al., 2014), and which involves faculty members, observers, and students. This paper focuses on the student point of view. The participants were students - of the Diploma Program in Preschool Education, Education for the 1 st to 6 th grades, and Teaching of English, and of the Bachelor's Program in Special Education- who had just finished the supervised practice. A questionnaire was administered and a panel discussion was conducted to analyze the supervised practice from the student point of view. The main findings point out the importance of the process. The conclusions include a number of student concerns related to training requirements in order to undertake appropriately the supervised practice. In addition, student recommendations are provided to the study programs.

Keywords. Pedagogy, students, training, supervised practice, observers.

La investigación realizada tuvo como propósito analizar la perspectiva del estudiantado, profesorado de cursoy personal tutor-observador, acerca del proceso de práctica supervisada llevado a cabo por el estudiantado de las carreras de pedagogía impartidas en la División de Educación Básica de la Universidad Nacional, en Costa Rica, a nivel de Diplomado en los énfasis de: I y II Ciclos, Preescolar, Enseñanza del Inglés y a nivel de Bachillerato en el énfasis de Educación Especial.

Enmarcado en una consulta del personal académico de la DEB relacionada directamente con los procesos de práctica supervisada y en concordancia con el documento Políticas y lineamientos que orientan el desarrollo y ejecución de la intervención pedagógica (Bejarano et al., 2007), el personal académico integrante del Programa de Desarrollo Académico y Gestión Organizacional (PDAGO) de la DEB se da a la tarea de actualizar y reforzar los lineamientos existentes que orientan el proceso de práctica supervisada del estudiantado y es así como se da la aprobación de las Disposiciones generales para la intervención pedagógica (Camacho et al., 2012), en la sesión ordinaria $n^{\circ} 10-2012$, del 27 de junio del año 2012, por parte del Consejo Académico de Unidad, de la División de Educación Básica. 
doi: http://dx.doi.org/10.15359/ree.19-2.23

URL: http://www.una.ac.cr/educare

CORREO: educare@una.cr

Los lineamientos aprobados regulan, a partir del II Ciclo del 2012, los procesos de práctica supervisada del nivel de Diplomado de las carreras de Pedagogía con énfasis en I y II Ciclos, Pedagogía con Énfasis en Educación Preescolar y Enseñanza del Inglés para I y II Ciclos, así como el proceso de práctica supervisada del nivel de Bachillerato de la carrera de Educación Especial con énfasis en Integración.

Cabe señalar que el proceso de intervención pedagógica (IP) permea todos los planes de estudio de dichas carreras y se visualiza como un compromiso que ha de asumir todo el profesorado a lolargo de su formación. Sin embargo, en este caso particular, la valoración realizada se circunscribe, exclusivamente, al momento de práctica supervisada en la que el alumnado, de manera más formal, se acerca a las instituciones educativas o espacios pedagógicos alternativos y toma a cargo un grupo de estudiantes con el cual desarrollan el proceso de enseñanza.

La práctica supervisada inicia con la matrícula del estudiantado en un curso cuyo profesor o profesora tiene a cargo la coordinación de dicha asignatura. De igual manera, se cuenta con la participación de profesorado observador, que con la conducción de la persona encargada del curso, van a estar desplazándose a las instituciones educativas o espacios pedagógicos alternativos, para valorar el desempeño del estudiantado.

Debido a que a partir de 2012 se pusieron en ejecución, por primera vez, los lineamientos aprobados por el Consejo Académico de Unidad para la regulación de los procesos de práctica supervisada, en ese momento se asume el reto de evaluar su ejecución durante el año 2012 y poder valorar y orientar su pertinencia y aplicabilidad desde la visión de los propios individuos interesados, en este caso particular, el estudiantado, el profesorado (tanto quien coordina como las personas observadoras o profesorado tutor).

La investigación de la que emerge el presente artículo no es el único esfuerzo que el personal académico de la División de Educación Básica ha realizado para valorar distintas etapas de los procesos de práctica supervisada, específicamente en lo referente a la incorporación del estudiantado en ámbitos educativos para su respectiva observación. Así, por ejemplo, pueden reseñarse los trabajos de Flores y Pereira (1991), quienes investigaron acerca de los aspectos metodológicos para la evaluación del proceso de práctica supervisada con estudiantes de la carrera de Ciencias de la Educación con énfasis en I y II Ciclos, modalidad presencial, según criterio de personal docente y directivo, correspondiente a la experiencia 1987-1988.

Gamboa (1997), quien sistematiza las vivencias del profesorado universitario acerca de las experiencias realizadas con el objetivo de mejorar la práctica supervisada, mediante el estudio denominado Evaluación de intervención pedagógica de 1987 a 1996, pretende consolidar la propuesta de intervención pedagógica vigente en ese momento y facilitar la toma de decisiones para su mejoramiento. Aporta un análisis e interpretación crítica de las diferentes experiencias mencionadas. Dentro de sus hallazgos explicita las vivencias de estudiantes (figura 1), los procesos que se desarrollaron, las relaciones que se establecen durante la práctica supervisada entre personal docente, personas observadoras, practicantes y estudiantado. 


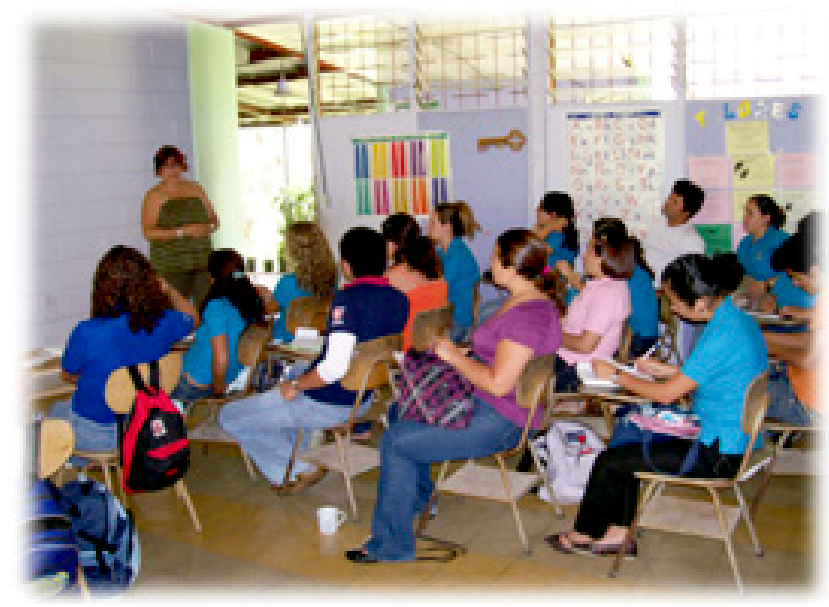

Figura 1. La intervención pedagógica involucra una serie de estrategias de coordinación que busca generar procesos reflexivos sobre la realidad educativa.

Posteriormente, Bejarano, Dobles, León y Quesada (2006) investigan el proceso de práctica supervisada en la formación de docentes de las carreras impartidas en la DEB mediante el desarrollo de un proyecto denominado Intervención pedagógica praxis desde la formación universitaria, cuyo objetivo fue analizar la práctica educativa desde la formación universitaria, retomando, para ello, los planes de estudio, la opinión estudiantil y conceptualizaciones del profesorado universitario y otros personas actoras del proceso.

El aporte del estudio, además de ofrecer información valiosa sobre la práctica supervisada y actividades relacionadas, brinda conclusiones en torno a su re-conceptualización y recomendaciones enfocadas a la selección tanto de las instituciones participantes como de las personas observadoras-tutoras.

Como seguimiento a dicha investigación y profundización de la temática, Herrera, Quesada y Rizo (2008) asumen la tarea de analizar el proceso del eje práctico pedagógico de las carreras impartidas en la DEB con miras al fortalecimiento de los planes de estudio, mediante la investigación denominada Intervención pedagógica: Praxis desde la formación universitaria (2007-2008). En un marco de investigación acción incorporaron la participación del personal académico y estudiantado de la DEB, analizaron el eje práctico pedagógico, el objetivo de la IP, las concepciones y expectativas sobre el eje mencionado. Asimismo, se examinaron datos relacionados con la opinión del estudiantado sobre el eje práctico pedagógico desde diferentes perspectivas tales como inserción paulatina al aula y dinámica socio-cultural e histórica. También se trabajaron datos sobre la realidad educativa, construcción y reconstrucción de teorías propias, relación teoría-práctica y enfoques de la práctica profesional. 
doi: http://dx.doi.org/10.15359/ree.19-2.23

URL: http://www.una.ac.cr/educare

CORREO: educare@una.cr

Chaves, Rizo y Vindas (2010) escriben un artículo denominado: Experiencias del curso "Intervención pedagógicaen laeducación preescolar:Lavisión delas académicas, docentes yestudiantes", en el que se hace un recorrido por los objetivos, experiencias y retos del curso, tomando en cuenta tanto las vivencias del equipo de académicas, que han guiado este proceso en los últimos dos años, así como también, las opiniones del estudiantado y del personal docente de preescolar.

Por otra parte, Miranda (2011), en el Informe del proceso de práctica supervisada desarrollado en la carrera de ly ll Ciclos, destaca la comunicación con las personas directoras de las instituciones educativas, los procesos de inducción con el personal anfitrión (quienes recibirían en su aula al estudiantado), así como la importancia de dejar en claro los compromisos adquiridos por el estudiantado, profesorado anfitrión y personal observador.

Badilla, Ramírez, Rizo y Rojas (2013) se proponen, en su proyecto La praxis profesional del docente en formación y del formador de formadores", generar espacios de reflexión-acción de las prácticas pedagógicas del docente que forma personal formador y estudiantado-futuro profesorado para fortalecer su práctica pedagógica.

Esta investigación valoró el proceso de articulación del eje práctico pedagógico (EPP) de las cuatro carreras de la División de Educación Básica mediante la ejecución de las estrategias denominadas auto-observación, incidente crítico, diario de docente y sistematización del propio modelo pedagógico, categorizadas en situaciones didácticas, disciplinarias, metodológicas, emocionales y situaciones emergentes.

Recientemente, Camacho y Rojas (2013) presentan el artículo titulado La mirada de las profesoras coordinadoras de la intervención pedagógica en la carrera de Pedagogía con Énfasis en I y II Ciclo con el objetivo de destacar (desde la visión de las académicas responsables) las acciones correspondientes a la coordinación, inducción y cierre del proceso de la Práctica Profesional Supervisada (PPS), a partir del curso Construcción Pedagógica desde el Aula Escolar de la carrera de Pedagogía con énfasis en I y II Ciclo de la Educación General Básica.

Entre los aportes se destaca que la intervención pedagógica involucra una serie de estrategias de coordinación que busca generar procesos reflexivos sobre la realidad educativa (figura 2). Al respecto, Camacho y Rojas (2013, p. 138) expresan que:

Se propone una práctica reflexiva, que implica valorar, por parte del estudiantado, su propia experiencia de práctica, construir nuevos conceptos e impulsar propuestas de mejora, de tal manera que el proceso adquiera sentido y significado, y se convierta en un espacio de investigación permanente y una oportunidad para perfilar su futura práctica profesional. 
Las autoras plantean que, para la realización de una apropiada coordinación de la IP, se deben ejecutar acciones que contextualicen este proceso de práctica a la realidad en el ámbito escolar y universitario. Para ello, desde el curso eje de la PPS se realiza una inserción práctica del estudiantado de manera analítica y crítica a espacios educativos. Estas acciones están direccionadas a mejorar la IP en términos curriculares, técnico-pedagógicos y logísticos entre las profesoras de curso y los profesores observadores en coordinación con el área administrativa de la DEB, por lo que se realizan procesos de inducción a estudiantes y profesores observadores y centros educativos; asimismo, al finalizar, se generan espacios de reflexión y sistematización del proceso vivenciado por el profesorado y el estudiantado (Camacho y Rojas, 2013).

Analizan los aspectos determinantes del proceso de coordinación realizado por el profesorado encargado, establecidos para el éxito del proceso de IP; indican las distintas acciones que se llevan a cabo para fortalecer el proceso, dentro de lo cual señalan que a nivel académico se da una elaboración de programas y cambios en el curso de Construcción Pedagógica desde el Aula Escolar a partir de las recomendaciones del informe de IP 2009, planificación de estrategias metodológicas de acciónreflexión, coordinación de giras pedagógicas y talleres con otras instancias educativas.

En relación con los aspectos técnico-pedagógicos y logísticos, se realiza una organización de trabajo con los profesores observadores, con base en los lineamientos de la práctica supervisada, y se brinda la información, distribución y seguimiento del estudiantado. Con respecto a la gestión administrativa, se realiza la selección del profesorado observador, realización de las cartas a centros educativos y personal docente anfitrión con información del estudiantado practicante, gestión de documentación para el estudiantado universitario, coordinación y asistencia de actividades de inducción, talleres, cierre del proceso, entre otros.

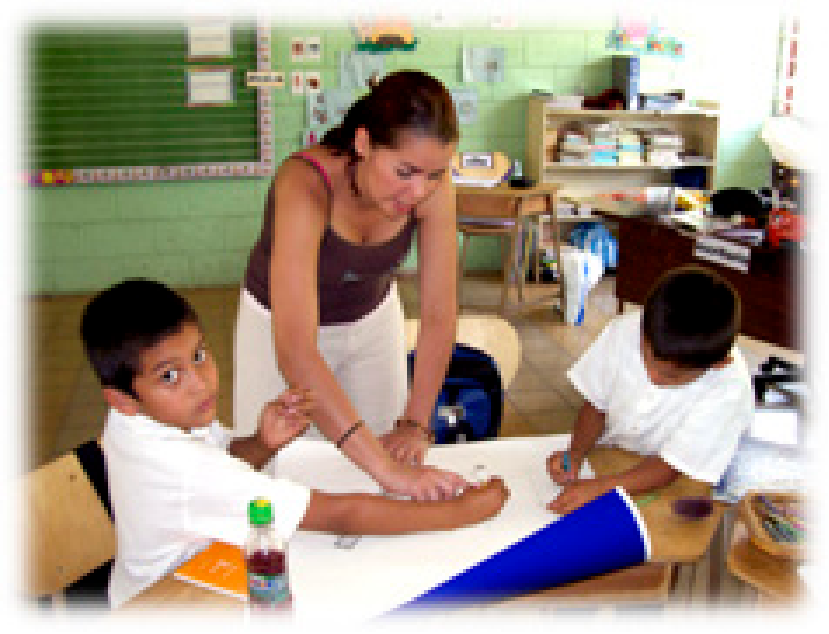

Figura 2. Una práctica reflexiva implica valorar, por parte del estudiantado, su propia experiencia de práctica, construir nuevos conceptos e impulsar propuestas de mejora. 
doi: http://dx.doi.org/10.15359/ree.19-2.23

URL: http://www.una.ac.cr/educare

CORREO: educare@una.cr

Como en todo proceso formativo, intervienen, durante la práctica supervisada, una serie de factores que incide y condiciona el desarrollo y evolución de cada estudiante en el escenario áulico, lo que los hace transformarse en procesos altamente complejos. Al respecto, Quesada (2013) en su artículo La intervención pedagógica como un reto de la formación universitaria: Hacia una práctica profesional articulada, expone una serie de retos o desafíos, así como diversas variables que deben valorarse para lograr espacios significativos que permitan a las futuras generaciones de docentes, la construcción de un modelo docente adecuado a las diferentes realidades educativas, a las cuales se enfrentarán a lo largo de su labor educativa. Estos desafíos concuerdan con lo expuesto por Villegas-Reimers y Ávalos (2003), quienes indican:

La antigua noción de que los maestros solamente transmiten conocimientos hace mucho dejó de existir. Hoy se espera que los maestros creen entornos que impulsen a sus alumnos a explorar, construir conocimiento y aprendizaje. Se espera que respondan a las necesidades sociales y de aprendizaje de sus alumnos, que se identifiquen con las familias y comunidades de los niños, y que trabajen con ellas. (p. 41)

Los aportes mencionados son solo algunos de los esfuerzos desarrollados en la División de Educación Básica, para una mejor comprensión de los procesos de intervención pedagógica, los ejes que permean los planes de estudio, las intencionalidades de la práctica supervisada, entre otros aspectos. Dichos esfuerzos plantean logros, necesidades y retos en busca de un proceso formativo integral del estudiantado y del diseño de planes de estudio que así lo permitan.

A continuación, se plantea una contextualización de la investigación realizada y se profundiza en los distintos esfuerzos que la unidad académica, a partir de las investigaciones de su personal académico, ha logrado desarrollar en procura de un análisis de la práctica supervisada desde distintas vertientes y con el objetivo prioritario de ofrecer una formación pertinente al futuro personal docente.

\section{Contextualización}

La División de Educación Básica (DEB), unidad académica del Centro de Investigación y Docencia en Educación (CIDE) de la Universidad Nacional, en Costa Rica, tiene a cargo la formación del estudiantado que se desempeñará en el campo educativo como licenciadas y licenciados en pedagogía, en los énfasis de l y ll ciclos, educación preescolar, educación especial, así como los bachilleres en enseñanza del inglés para I y II ciclos. 
Es importante señalar que, desde una perspectiva contemporánea de la pedagogía, han de tomarse en consideración distintas aristas del proceso educativo intervinientes en la realidad de aula (figura 3); así, por ejemplo, ha de tenerse presente que los contenidos, estrategias, actividades, recursos, objetivos pedagógicos, dinámicas de aula, entre otros, no pueden estar descontextualizados de una realidad; por ello, recurrir al diagnóstico en busca de determinar intereses, necesidades, situaciones y problemáticas son solo algunos de los elementos que deben servir de orientación a la práctica profesional supervisada docente de la comunidad educativa en la que se está inserto (Miranda, 2011).

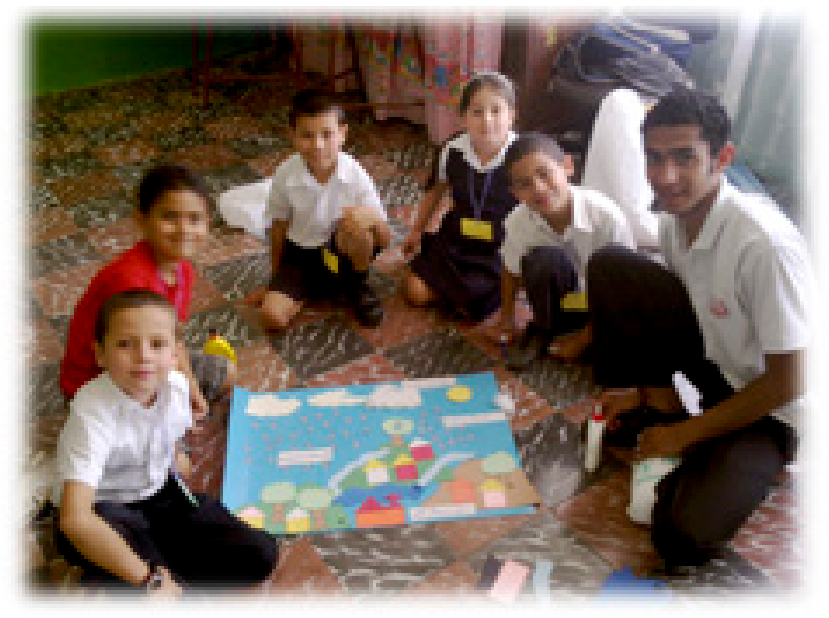

Figura 3. Desde una perspectiva contemporánea de la pedagogía, han de tomarse en consideración distintas aristas del proceso educativo intervinientes en la realidad de aula.

Los procesos meta cognitivos se enriquecen cuando, mediante la reflexión, el estudiantado en interacción con el profesorado y personal observador tutor se plantean el análisis de sus propias prácticas y, como señalan Boggino y Rosekrans (2007), cuando se enfrentan a conflictos, puntos de vista diversos, conocimientos y creencias. De ahí la importancia de que la práctica supervisada sea visualizada como una oportunidad más de crecimiento del estudiantado y de fortalecimiento, también, del profesorado: ha de constituirse, por tanto, en un espacio de desarrollo mutuo.

Dentro de los planes de estudio de las carreras indicadas, se comparte la visión de que el estudiantado, desde el inicio, debe acercarse al campo educativo, como una forma de enlazar los planteamientos teóricos propios de la formación docente, con las realidades educativas del país. Por ello, en los planes de estudio permea la idea de que la intervención pedagógica es una responsabilidad compartida entre el estudiantado y el cuerpo docente a lo largo de toda la formación. Y en el desarrollo de los distintos cursos de las carreras, se tiene un contacto permanente con las realidades educativas mediante técnicas observacionales que aportan elementos al análisis teórico de los distintos cursos, mediante procesos reflexivos contextualizados en las realidades educativas del país. De manera que la realidad misma constituye un valioso insumo en la formación. Al respecto, Bruns y Luque (2014) señalan: 
doi: http://dx.doi.org/10.15359/ree.19-2.23

URL: http://www.una.ac.cr/educare

CORREO: educare@una.cr

Los extensos cambios observados en la educación mundial constituyen un desafío adicional. Los objetivos tradicionales de los sistemas nacionales de educación y el paradigma clásico de interacción entre profesor y alumno convirtieron a los profesores en el eje de la transmisión de conjuntos de conocimientos específicos a los estudiantes en el aula. En el nuevo paradigma, los profesores ya no son la única ni la principal fuente de información y conocimientos de que disponen los estudiantes. (p. 50)

Desde esa visión más amplia de la educación, donde se amplían las fuentes de información y conocimientos, cabe destacar los planteamientos de Sanjurjo (2009), quien señala que el proceso reflexivo es:

Aquel que permite darnos cuenta y dar cuenta de nuestras propias acciones y de la diversidad de condicionantes que las determinan. La reflexión se constituye en un puente entre la teoría y la práctica, entre el pensamiento y la acción, entre los materiales curriculares, lo metodológico y los problemas que nos plantea la realidad. (p. 23)

Como parte de dicho proceso, en las carreras de la DEB existe un momento importante en la formación del estudiantado, referido específicamente al período en el cual, de una manera más sistemática y evaluada, se acercan al campo educativo activa y participativamente. Dicho momento se caracteriza por una práctica supervisada en instituciones o espacios pedagógicos alternativos y es al que hace referencia específica la investigación de la que emerge este artículo.

El grupo investigador comparte la idea de que:

La Intervención Pedagógica [en nuestro caso particular, entendido específicamente como la práctica profesional supervisada] como proceso vivencial, constituye un espacio de reflexión-construcción, tanto para la apropiación teórica y metodológica del conocimiento pedagógico, como para el desarrollo innovador y significativo de la práctica pedagógica de cada estudiante-docente, al final de su formación en el nivel de Diplomado. Representa una significativa experiencia integral de aprendizaje que inserta al estudiante practicante en un contexto educativo, donde además de articular la teoría con la práctica a través de su desempeño pedagógico, demuestra las competencias básicas para desenvolverse profesionalmente como docente. (Miranda, 2011, p. 1)

Agrega el autor que, en el marco de la intervención pedagógica, la institución educativa ha de verse como un espacio vivo y cambiante en continua construcción, por lo cual se requiere que el estudiantado practicante asuma un papel transformador, donde una tarea importante sea la reflexión sobre su propia práctica, con miras a constituirse en una persona educadora que la niñez, juventud y y personas adultas requieren (figura 4). 
Por otra parte, Miranda (2011) señala que, desde la perspectiva de la formación docente, los procesos de práctica profesional supervisada o intervención pedagógica en contextos educativos reales constituyen una valiosa experiencia que brinda, a cada estudiante, la oportunidad de construir saberes que van más allá del aula universitaria. La dinámica institucional, la interacción con la comunidad educativa y el modelaje a partir de la experiencia cotidiana son algunas de las experiencias que ofrecen estos espacios de aprendizaje. Como lo señala Correa (2011):

El período de práctica constituye un espacio potencialmente favorable para el desarrollo profesional del futuro docente. Espacio de transición, punto deencuentroentre dos mundos -profesional y universitario- ejemplo concreto de alternancia, la práctica profesional le permite al estudiante no sólo la construcción y la manifestación de competencias sino, además, la integración de saberes de naturaleza diversa y la apropiación de un modelo identitario. (p. 81)

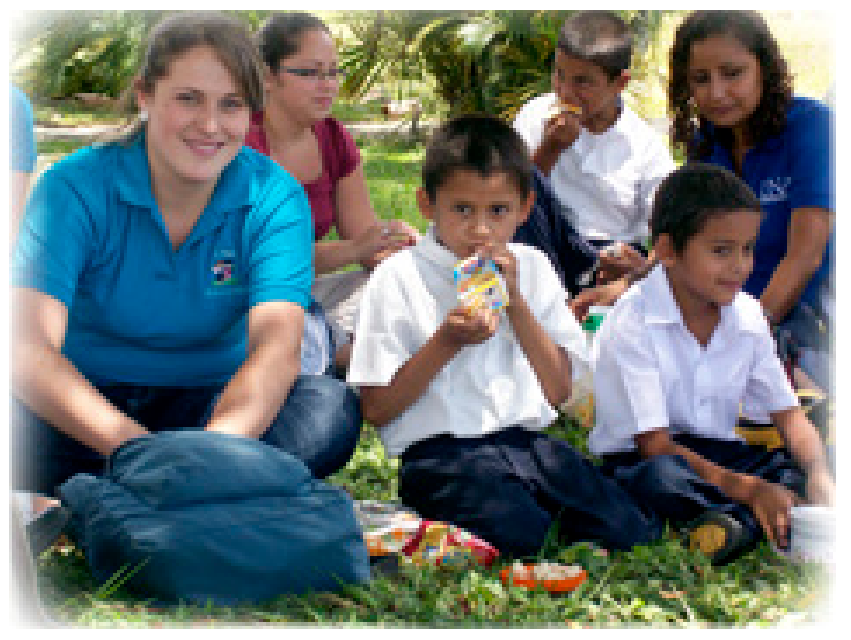

Figura 4. En el marco de la intervención pedagógica, la institución educativa ha de verse como un espacio vivo y cambiante en continua construcción.

Agrega Miranda (2011) que, en torno a la práctica supervisada, interviene una diversidad de elementos condicionantes que inciden en estos procesos, tal es el caso del perfil de ingreso del estudiantado al iniciar la carrera, el desarrollo de habilidades comunicativas durante la formación, el dominio conceptual en cada una de las asignaturas del currículo escolar vigente, así como las estrategias didácticas diferenciadas para cada área. Todo esto acompañado de una toma de conciencia que le permita, a cada estudiante, conocer la realidad educativa en la que eventualmente deberá intervenir como actor o actora imprescindible de la sociedad. 
doi: http://dx.doi.org/10.15359/ree.19-2.23

URL: http://www.una.ac.cr/educare

CORREO: educare@una.cr

Al respecto, Quesada (2013) advierte:

Ser docente implica, entre muchas otras cosas, ser un conocedor del referente histórico social de la humanidad, con un bagaje cultural amplio que le permita generar relaciones socio-políticas que le faciliten la comprensión de cómo las estructuras políticas, ideológicas, religiosas y culturales influyen de manera significativa en la construcción social existente; valorar, así, aspectos apropiados e inapropiados que han dado como resultado el momento histórico actual, para lo cual necesita un grado de objetividad que le facilite una lectura crítica de la realidad contemporánea. (p. 173)

Entre otros aspectos que van más allá de la labor pedagógica, Quesada (2013) menciona una serie de desafíos que deben considerarse en la formación de maestras y maestros, como son el alcance de ciertas habilidades implícitas de su labor docente (figura 5); habilidades que involucran la capacidad de análisis, de pensamiento crítico, de generar estrategias amparadas en diferentes enfoques investigativos, de sistematizar información, de dominar principios básicos de administración educativa -aspecto relevante para poder cumplir con requerimientos administrativos-, del manejo legal y procedimental de la aplicación de adecuaciones curriculares para garantizar el derecho y la necesidad de personas con necesidades educativas especiales (N.E.E), así como poseer un amplio y preciso conocimiento del marco legal relacionado con el sector educativo, entre otros.

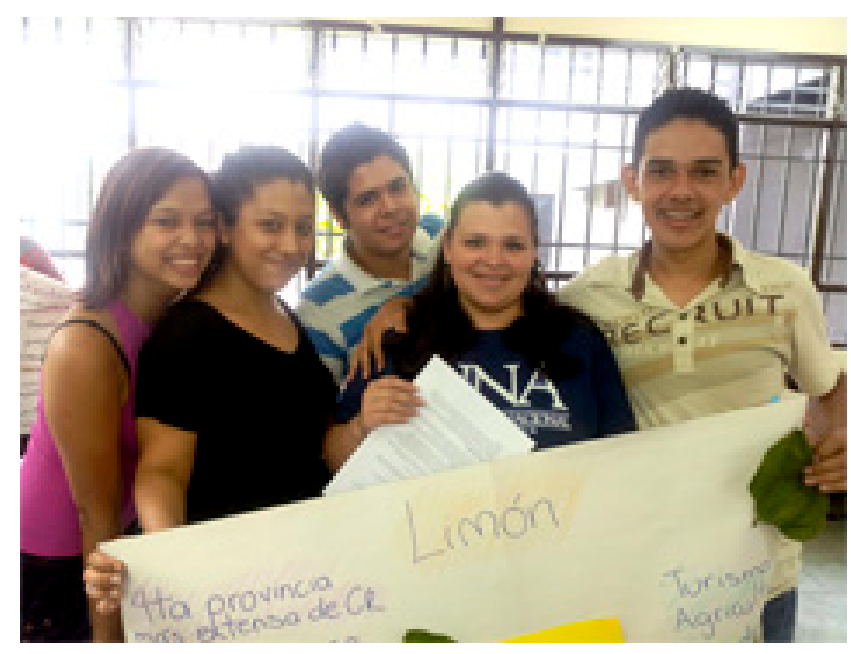

Figura 5. La dinámica institucional, la interacción con la comunidad educativa y el modelaje a partir de la experiencia cotidiana son algunas de las vivencias que brindan estos espacios de aprendizaje. 
Desde esta visión, resulta impostergable concebir la formación docente como un conjunto de procesos articulados, no solo entre las diversas dimensiones de la oferta curricular de un plan de estudios, sino en constante reflexión a partir de lo que la realidad y la institución educativa demanda (figura 6).

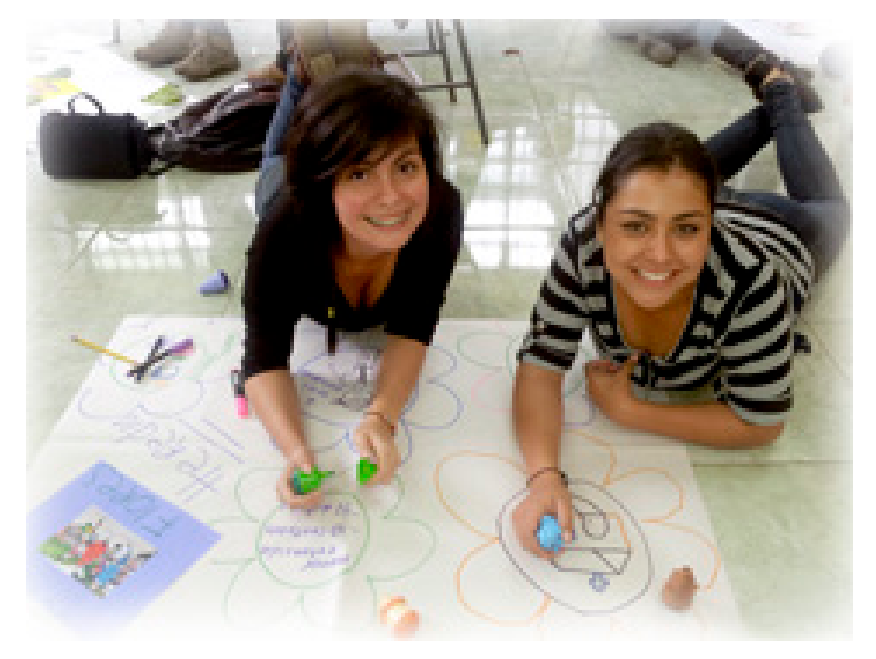

Figura 6. Los procesos de práctica deben aportar, a las futuras y futuros docentes, vivencias de aula que promuevan estrategias metacognitivas que permitan al estudiantado analizar sus propias prácticas y fortalecer, de esa manera, sus vivencias en el ámbito educativo.

Para Quesada (2013), la formación de un profesional en educación es amplia, precisa compleja y pertinente:

Asumir un grupo escolar no es una tarea fácil en la que prive la improvisación o la aplicación de estrategias sin una adecuada plataforma científica pedagógica. De este principio se parte para considerar que los profesionales en educación son científicos sociales y que su papel es quizás uno de los más importantes dentro de la sociedad, ya que procura, desde su dimensión ejecutiva, el desarrollo de habilidades y destrezas que le permitirán a los sujetos un desarrollo armonioso, tanto en el plano intrapersonal, como interpersonal, y los convertirán en agentes proactivos en el plano social. (p. 176)

Al destacar la trascendencia de la labor docente, el autor no solo advierte que deben visualizarse las funciones y responsabilidades que implica la gestión de la educación en la praxis y en contextos escolarizados, sino que plantea interrogantes a quienes toman las decisiones y asumen la formación de maestras y maestros en escenarios universitarios (figura 7). 


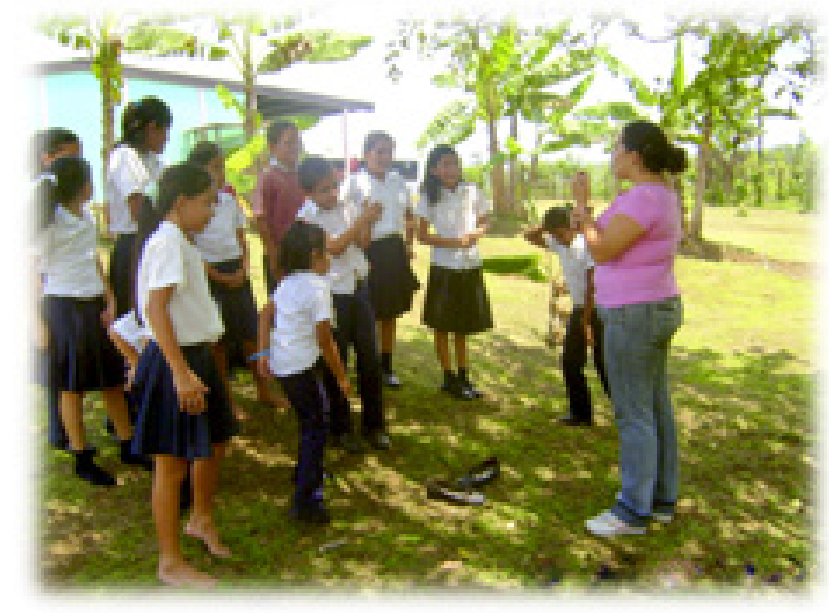

Figura 7. Las vivencias durante la práctica constituyen una valiosa experiencia que brinda, a cada estudiante, la oportunidad de construir saberes que van más allá del aula universitaria.

Quesada (2013) concluye reflexionando en torno a las siguientes interrogantes:

¿Se puede garantizar que los procesos de acercamiento a la realidad educativa se encuentran debidamente organizados y enfocados hacia el mejoramiento del quehacer educativo?, ¿son en realidad procesos secuenciales articulados en un desarrollo gradual de habilidades y destrezas profesionales y personales?, ¿son las experiencias compartidas por los estudiantes universitarios un espacio para la reflexión académica y para la revalorización del discurso teórico?, ¿se ajustan los procesos evaluativos universitarios a la construcción cognitiva que han alcanzado los estudiantes de acuerdo con su vivencia y madurez académica?, ¿resultan ser estos procesos naturales, enriquecedores, diversos y bien orientados para una transformación positiva de la sociedad?, ¿es compatible el modelaje profesional de las docentes anfitrionas con la línea formativa que tiene la unidad académica?, ¿se abarcan inmediatamente desde la formación universitaria aquellos incidentes críticos que desestabilizan la intervención pedagógica? (p. 182)

Lo anterior alerta acerca de la responsabilidad y compromiso que deben asumir, no solo los actores directos de estos procesos tales como las personas formadoras y el estudiantado de pedagogía, sino que debe involucrar, de forma articulada, a las personas y percepciones que gestan las políticas curriculares en los distintos centros de formación docente. Como lo menciona Escobar (2007):

Es innegable que la Práctica Profesional Docente conforma un entramado en el que inciden múltiples factores y subjetividades, no siempre explícitos que obligan desde la acción consciente y reflexiva a observar de manera atenta la práctica propia y las otras prácticas. (p. 193) 
En esa misma línea de pensamiento, pero enfatizando más en la propia experiencia del estudiantado durante el proceso de práctica supervisada, Bejarano et al. (2006, p. 83) expresan la necesidad de

Construir una experiencia que vaya más en el sentido de una construcción y reconstrucción personal o endógena, en la cual el mismo sujeto que vivencia el proceso formativo determine sus propias fortalezas y debilidades y establezca, con el apoyo de sus profesores u otras personas o recursos, las medidas pertinentes para su propio crecimiento.

En torno a la formación, Alliaud y Antelo (2009) señalan:

Los procesos de formación deben ser sostenidos en el tiempo para fortalecer el oficio de cada enseñante, pues la tarea docente exige hoy una cantidad innumerable de requisitos que son necesarios considerar para no alejarse del oficio encerrándose en un castillo teórico sin estudiantes, sin colegas y sin una realidad a la cual responder. (p. 63)

En el sentido señalado, cobra importancia la necesidad de que ese proceso de observación de la práctica supervisada esté permeado no solo por el señalamiento de parte del profesorado observador de este, sino que se promuevan estrategias metacognitivas que permitan al estudiantado analizar sus propias prácticas y fortalecer, de esa manera, sus vivencias en el ámbito educativo (figura 8). Dentro de la perspectiva indicada, Herrera et al. (2008, p. 152) expresan que:

Es importante que los profesores evidencien con sus estudiantes sus propias reflexiones de su prácticas pedagógicas (praxis), volviéndose de esta manera una herramienta de auto reflexión propia de la dinámica del aula universitaria, es decir, evidenciar dispositivos para el desarrollo de la conciencia crítica de su práctica por medio del análisis de nuestras propias prácticas y estrategias para tomar conciencia desde donde estamos formando.

Se comparte lo expresado por Sanjurjo (2002), quien concibe la meta cognición desde varias aristas, no solo como reflexión del conocimiento, aplicable a situaciones diversas, sino también como una estrategia útil para mejorar el aprendizaje, capaz de identificar las potencialidades individuales y también determinar los aspectos que pueden ser objeto de mejora. Es, por tanto, una valiosa herramienta para el aprendizaje y la autovaloración. Las investigaciones del personal académico de la División de Educación Básica, en relación a la IP y práctica profesional supervisada, brindan valiosos aportes para el fortalecimiento de los planes de estudio de las distintas carreras. El componente de IP, permea los planes de estudio y enfatiza especialmente, en brindar al estudiantado la oportunidad de enriquecer su formación mediante la práctica supervisada, con miras a que el estudiante en su futura inserción laboral, se desempeñe de manera consciente, renovada, transformadora y eficaz. 


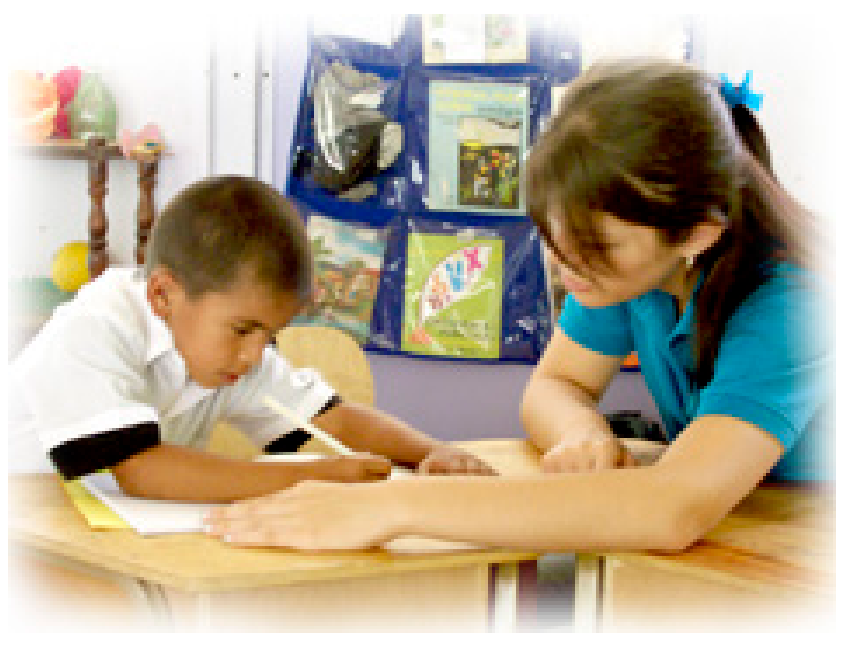

Figura 8. Cada proceso de intervención pedagógica inserta a cada estudiante practicante en un contexto educativo, donde, además de articular la teoría con la práctica a través de su desempeño pedagógico, demuestra las competencias básicas para desenvolverse profesionalmente como docente.

Es esperable que la práctica supervisada le permita al estudiantado poner en ejecución esas capacidades y convertirse en un agente reflexivo, creativo y propositivo. En el contexto de búsqueda de una práctica docente reflexiva y un aprendizaje transformacional, cabe destacar los planteamientos de Boggino y Rosekrans (2007), quienes señalan que "la práctica reflexiva tiene que ir más allá: tiene que transformar creencias, conocimientos y conductas, tocando así aspectos epistemológicos, teóricos e ideológicos. Implica algo más que puntos de vista" (p. 143).

A manera de cierre, es posible determinar que la DEB, de manera permanente, ha tenido el interés de realizar valoraciones, análisis y profundización de las propuestas de los distintos planes de estudio de sus carreras acerca de la IP y la práctica supervisada. Los trabajos mencionados han enfatizado en distintos aspectos propios de la IP dentro de los planes de estudios, aspectos valiosos de ser considerados como contextualización de la investigación realizada (Camacho et al., 2014), la cual se constituye en un insumo más, abordando el análisis del período de práctica supervisada que vivenció el estudiantado de las distintas carreras en áreas educativas (instituciones $u$ otros espacios pedagógicos alternativos) con el propósito de fortalecer su formación como personal docente del futuro (figura 9).

En torno a esta nueva visión, Terigi (2009) plantea que el cambio en la formación del profesorado de docentes debería asumir cuatro desafíos:

La formación de los profesores para nuevas funciones (como las tutorías o las clases de apoyo), la reformulación de la pedagogía de la formación, la cuestión de las tecnologías de la información y comunicación, y la singularidad de los procesos de incorporación de los profesores noveles a sus puestos de trabajo. (p. 123) 
Este proceso se caracteriza por definir un tiempo específico para la ejecución del trabajo estudiantil con el aporte de profesoras y profesores observadores, cuya tarea primordial es el fortalecimiento de los aprendizajes para una formación integral del estudiantado-docente.

Es válido mencionar que los hallazgos han ido fortaleciendo los procesos de práctica supervisada y han sido elementos básicos para plasmar los lineamientos que rigen dicho proceso en la Unidad Académica. A partir de los aportes de las valoraciones hechas por el personal académico de la DEB en distintos momentos, se ha enriquecido el documento de lineamientos para la práctica supervisada aprobado por el Consejo Académico de la DEB, dentro de las funciones que le competen.

Como parte de la implementación de dichos lineamientos y de la investigación realizada, se presentan, a continuación, los procedimientos seguidos y los principales hallazgos a partir de la participación estudiantil en la valoración del proceso de práctica.

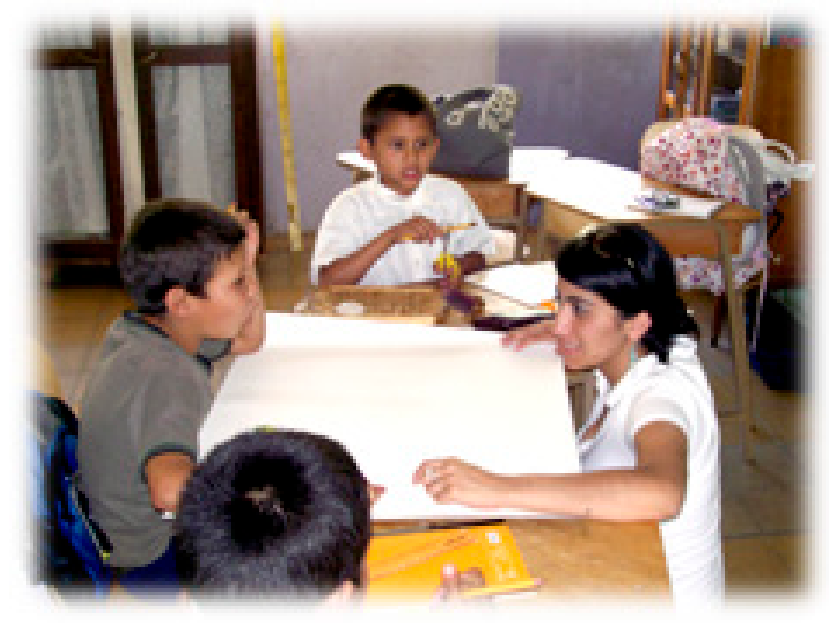

Figura 9. Todas las experiencias que surgen de la práctica deben ir acompañadas de una toma de conciencia que le permita, a cada estudiante, conocer la realidad educativa en la que eventualmente deberá intervenir como actor o actora imprescindible de la sociedad.

\section{Metodología}

\section{Tipo de estudio}

Dentro de una perspectiva naturalista, se realizó una valoración de la práctica supervisada, específicamente centrada en la incorporación formal del estudiantado en las instituciones educativas o espacios pedagógicos alternativos, como parte de su formación en los siguientes cursos que tienen como objetivo primordial la coordinación de los procesos de práctica supervisada. Los cursos, según carrera son: 
doi: http://dx.doi.org/10.15359/ree.19-2.23

URL: http://www.una.ac.cr/educare

CORREO: educare@una.cr

- DBH-211 Intervención Pedagógica en la Educación Preescolar. II Diplomado en la carrera de Pedagogía con Énfasis en Educación Preescolar.

- DBJ-212. Construcción Pedagógica desde el Aula Escolar. II Diplomado en la carrera de Pedagogía con Énfasis en I y ll Ciclo.

- DBL-207. Praxis Pedagógica en el Aula Escolar. II Diplomado en la carrera de Enseñanza del Inglés para I y II Ciclos.

- DBK-413. Intervención Pedagógica IV Bachillerato en la carrera de Educación Especial con Énfasis en Integración.

Para ello, se recurrió a obtener la visión de los principales actores en dicho proceso, prioritariamente bajo un enfoque de tipo cualitativo.

Este tipo de acercamiento metodológico permitió recuperar las impresiones, vivencias y perspectivas más cercanas de quienes realizaron su ejercicio como estudiantado-practicante en instituciones educativas costarricenses y en espacios pedagógicos alternativos y que aspiraban a graduarse como docentes de Preescolar, I y II ciclos, Enseñanza del inglés y Educación Especial.

\section{Participantes}

Participó el estudiantado del Diplomado de las carreras en Pedagogía con énfasis en Preescolar, I y II Ciclos, Enseñanza del Inglés y Educación Especial

Todas las personas participantes lo hicieron por voluntad, a partir de un proceso de invitación que se les extendió, haciéndoles ver la necesidad de constituirse en las voces que permitieran un acercamiento a procesos valorativos a raíz de la implementación de los nuevos lineamientos que rigen la práctica supervisada.

Para el presente artículo se retoman los aportes brindados exclusivamente por 16 estudiantes ( 04 estudiantes por carrera), quienes se hicieron presentes de manera voluntaria a la convocatoria cursada.

\section{Instrumentos}

Para la valoración del proceso de práctica supervisada, llevado a cabo por el estudiantado de las carreras de la División de Educación Básica a nivel de Diplomado en los énfasis de I y II ciclos, Preescolar y Enseñanza del Inglés, así como de Bachillerato en Educación Especial, los instrumentos que se diseñaron fueron validados mediante criterio de jueces, en su forma y contenido. A continuación se describe cada uno de ellos. 
doi: http://dx.doi.org/10.15359/ree.19-2.23

URL: http://www.una.ac.cr/educare

Valoración de la práctica supervisada, desde la perspectiva del estudiantado: en este instrumento, se solicitó indicar la carrera que cursaban y se aplicó al estudiantado que acababa de finalizar el proceso de práctica supervisada en los distintos énfasis. De igual manera, se les pidió indicar, en orden de importancia, tres fortalezas de la práctica supervisada, así como indicar en orden de importancia tres aspectos que, desde su perspectiva, deben ser mejorados. Para finalizar se les solicitaron, en orden de importancia, tres sugerencias que, desde su visión, podrían propiciar el mejoramiento del proceso de práctica supervisada.

Técnica de conversatorios conel estudiantado: el conversatorio como técnica permite analizar una temática determinada, de manera más espontánea por parte de las personas participantes. En este caso particular, lo fue el proceso de práctica supervisada recién vivido. Es una técnica que favorece la profundización temática mediante una discusión guiada (Babbie, 2000).

El conversatorio se conceptualiza como un grupo formado por un número impar de participantes, puede apoyarse de distintos recursos para la recopilación de información, en el caso particular de la investigación realizada, fue el uso de crónicas en versión física y digital. De igual manera, se señala como sugerencia que la realización de este no exceda la hora y media como tiempo razonable (Pulido, 1992).

En el sentido señalado, Flick (2004, citado por Pereira, 2010) indica que los conversatorios "estimulan a los que responden y los apoyan en el recuerdo de los acontecimientos, y pueden llevar más allá las respuestas del entrevistado individual" (p. 271).

Ha de destacarse que el haber realizado la aplicación de los cuestionarios y el conversatorio recién terminado el proceso de práctica supervisada, a criterio del equipo investigador, favoreció que las personas participantes tuvieran presentes muchas vivencias y eso permitió contar con mayores elementos para la valoración de la experiencia desarrollada.

\section{Procedimiento}

Como parte de los procedimientos seguidos es importante señalar lo siguiente:

- Se cursó una invitación al estudiantado, con el propósito de recopilar sus opiniones acerca del proceso de práctica supervisada que se acababa de realizar.

- En la sesión de conversatorio se organizó la actividad en dos fases, en la primera se hizo aplicación del cuestionario correspondiente por parte de un miembro del equipo del Programa de Desarrollo Académico y Gestión Organizacional (PDAGO) de la División de Educación Básica (DEB), quien también estuvo a cargo de la segunda fase correspondiente al desarrollo y conducción del conversatorio. 
doi: http://dx.doi.org/10.15359/ree.19-2.23

URL: http://www.una.ac.cr/educare

CORREO: educare@una.cr

- Los miembros del equipo fueron encargados de recopilar la crónica del conversatorio que se estaba llevando a cabo, previo consentimiento de las personas participantes.

- Para el análisis de datos, se hizo transcripción textual de respuestas al cuestionario y se complementaron los datos con la transcripción de las crónicas realizadas por el equipo de PDAGO.

- Una vez realizadas todas las transcripciones, la información se vació en matrices organizadas por pregunta y por carrera, de manera que se visualizara claramente las semejanzas y diferencias entre los grupos participantes.

- Para el análisis de los datos se recurrió a la triangulación, con el propósito de valorar de manera holística la práctica supervisada llevada a cabo por parte del estudiantado de los distintos énfasis de las carreras de pedagogía.

\section{Principales hallazgos}

En este apartado se presentan los hallazgos más relevantes acerca de la valoración de la práctica supervisada desde la perspectiva del estudiantado. Se ha organizado la información mediante tablas y figuras. Para ello, se han retomado las categorías de análisis a las que responden los instrumentos, con el propósito de sintetizar, de manera más organizada, la información recopilada (figura 10).

Cabe señalar que una vez realizada la transcripción de respuestas y el vaciado de toda la información, los datos fueron contrastados mediante el proceso de triangulación por categorías de análisis, de modo que emergieran, de manera más clara, las semejanzas y las diferencias Mediante categorías de análisis, se presenta a continuación la información recopilada. Es importante aclarar que las categorías utilizadas se apoyan, a su vez, en categorías derivadas de análisis para facilitar la organización de los datos recopilados y la mejor comprensión de estos.

\section{Valoración de la práctica supervisada desde la visión estudiantil}

Se presentan a continuación las opiniones expresadas por el estudiantado participante, acerca de la valoración de la práctica supervisada, considerando categorías derivadas de análisis, referidas a: el papel del personal docente anfitrión, así como los elementos del entorno institucional que favorecieron o limitaron el aprendizaje durante el proceso de práctica supervisada y, por último, pero no menos importante, los mayores aportes que a su criterio les brindó la experiencia. 
doi: http://dx.doi.org/10.15359/ree.19-2.23

URL: http://www.una.ac.cr/educare

CORREO: educare@una.cr

Tabla 1

Opiniones estudiantiles acerca del papel que tuvo la persona docente-anfitriona en su proceso de práctica supervisada

\begin{tabular}{|c|c|c|c|c|}
\hline & Pedagogía I y II ciclo & Enseñanza del Inglés & Educación Preescolar & Educación Especial \\
\hline $\begin{array}{l}\text { Opiniones } \\
\text { estudiantiles }\end{array}$ & $\begin{array}{l}\text { - La maestra la apoyó, le } \\
\text { dio espacios, le tiene } \\
\text { confianza. } \\
\text { - Se rescata lo bueno, pero } \\
\text { el papel no fue lo mejor, } \\
\text { está consumida por el } \\
\text { sistema, deja de lado lo } \\
\text { aprendido. Improvisa y } \\
\text { usa el libro de texto, me la } \\
\text { impuso el director. } \\
\text { - A uno le asignaban la } \\
\text { maestra, a mí me dio la } \\
\text { libertad y me vieron como } \\
\text { la otra más. } \\
\text { - Sabían más de lo que } \\
\text { daban. } \\
\text { - Le ha permitido trabajar } \\
\text { libremente. } \\
\text { - Mala experiencia el } \\
\text { papel de la docente } \\
\text { es determinante, } \\
\text { el contenido es lo } \\
\text { predominante. } \\
\text { - Al llegar uno con el } \\
\text { planeamiento y los } \\
\text { materiales le decía que } \\
\text { no hiciera eso y le decía } \\
\text { que improvisara. Llegó a } \\
\text { esta maestra porque se la } \\
\text { impuso el director. }\end{array}$ & $\begin{array}{l}\text { - Me ha dado apoyo, no } \\
\text { era la mejor, tendía a } \\
\text { etiquetar a los niños y } \\
\text { afectó mi rendimiento. } \\
\text { - No se le veían ganas ni } \\
\text { esmero, se presentó ese } \\
\text { inconveniente. } \\
\text { - Se nota algún grado de } \\
\text { indiferencia. } \\
\text { - La maestra llama la } \\
\text { atención y pone reglas } \\
\text { muy limitantes, cuando la } \\
\text { Ilegan a observar uno no } \\
\text { puede manejar el grupo } \\
\text { porque ella intervenía } \\
\text { y tomaba el grupo. Si } \\
\text { los niños hablaban y } \\
\text { trabajaban a mí no me } \\
\text { molesta. } \\
\text { - Dio un buen apoyo, pero } \\
\text { sus ganas de trabajar y } \\
\text { estar con los chicos no } \\
\text { eran las mejores, uno se } \\
\text { desmotiva cuando ve } \\
\text { estas actitudes de las } \\
\text { maestras le afecta a uno, } \\
\text { hubo confianza, pero } \\
\text { siempre se presentó esto. } \\
\text { - A la hora de llamar la } \\
\text { atención ella no dejaba } \\
\text { que uno asumiera, sino } \\
\text { que ella daba órdenes } \\
\text { porque es su grupo. Ven } \\
\text { desorden o no lo dejan a } \\
\text { uno ordenar el grupo. }\end{array}$ & $\begin{array}{l}\text { - A mí me fue muy bien, } \\
\text { pero me habría gustado } \\
\text { más tener apoyo, ella } \\
\text { me dejó sola, a veces } \\
\text { necesitaba ayuda y ella } \\
\text { "era como celosa de lo } \\
\text { que sabía" y no me quería } \\
\text { decir sus estrategias, tenía } \\
\text { recelo, hizo falta apertura } \\
\text { y acompañamiento. } \\
\text { - No comparte su } \\
\text { experiencia la hace sentir } \\
\text { como asistente. } \\
\text { - Tuvo suerte. }\end{array}$ & $\begin{array}{l}\text { - La profesora es de } \\
\text { problemas emocionales, } \\
\text { ha sido apoyo y guía } \\
\text { porque tienen mucha } \\
\text { experiencia, ella atendía } \\
\text { estudiantes, su función } \\
\text { debería ser de apoyo } \\
\text { pues no conocen los } \\
\text { estudiantes. } \\
\text { - Quedé satisfecha con } \\
\text { la docente anfitriona, } \\
\text { es un modelo, aprendí } \\
\text { como trabajar control } \\
\text { de esfínteres y } \\
\text { compañerismo, me ha } \\
\text { dado apoyo. } \\
\text { - Apoyo y guía para } \\
\text { estudiantes con } \\
\text { situaciones de conducta. } \\
\text { - Las maestras deberían } \\
\text { quedarse con nosotras. } \\
\text { - Muy abierta, flexible y } \\
\text { dispuesta a enseñar. }\end{array}$ \\
\hline No contesta & -- & 02 & 03 & 04 \\
\hline
\end{tabular}


doi: http://dx.doi.org/10.15359/ree.19-2.23

URL: http://www.una.ac.cr/educare

CORREO: educare@una.cr

Es interesante señalar que los datos que aporta el estudiantado que vivenció el proceso de práctica supervisada acerca del profesorado anfitrión (que les recibió en las instituciones educativas o espacios pedagógicos alternativos) y que se reflejan en la tabla 1 plantean posiciones positivas y negativas.

Destacan positivamente el hecho de que algunas de las personas docentes les dejaron trabajar con libertad y sintieron su apoyo, lo cual lo expresan así:"Muy abierta, flexible y dispuesta a enseñar". No obstante lo dicho, en algunas frases destaca el estudiantado aspectos positivos mezclados con señalamientos que a su criterio afectaron su experiencia de práctica, dentro de los que es posible destacar los siguientes: Me ha dado apoyo, no era la mejor, tendía a etiquetar a los niños y afectó mi rendimiento," A mí me fue muy bien, pero me habría gustado más tener apoyo, ella me dejó sola, a veces necesitaba ayuda y ella 'era como celosa de lo que sabía' y no me quería decir sus estrategias, tenía recelo, hizo falta apertura y acompañamiento".

Si se analizan de manera más detallada los datos de la tabla 1, es posible señalar que las valoraciones estudiantiles son mayoritariamente negativas, siendo variados los argumentos que permiten este señalamiento y que a criterio nuestro han de ser retomados para buscar mejores opciones para una práctica supervisada más ejemplarizante y modeladora de espacios aprendientes.

Las estudiantes participantes también mencionan aspectos negativos referidos al hecho de que el profesorado anfitrión suele ser asignado por la persona directora de las instituciones y señalan que muchas veces se les dificulta el trabajo con el grupo, pues la persona docente suele poner las reglas, límites y manejar la disciplina del grupo, lo cual entorpece su labor como estudiante-practicante.

Es crítico el estudiantado al señalar, por ejemplo, que alguien del personal docente anfitrión se ha plegado a un sistema educativo carente, así por ejemplo señalan: "está consumida por el sistema, deja de lado lo aprendido. Improvisa y usa el libro de texto, me la impuso el director". Otro estudiante señala: "Al llegar uno con el planeamiento y los materiales le decía que no hiciera eso y le decía que improvisara".

Los aspectos señalados por el estudiantado son valiosos y han de constituirse en elementos a retomar para la planificación de los procesos de práctica supervisada, pues es esperable que dichas experiencias sean formadoras y clarificadoras de la función docente, aspecto que a nuestro criterio puede ser analizado a lo interno de las carreras en procura de buscar alternativas para su fortalecimiento, quizá mediante la escogencia de algunas instituciones modelo o personas anfitrionas que muestren disposición y apertura para coformar al estudiantado.

Consideramos importante reforzar los procesos de inducción al personal docente anfitrión, personal directivo, profesorado observador y estudiantado universitarios pues, como lo señalan Camacho y Rojas (2013), son determinantes para el éxito de la práctica supervisada. 
doi: http://dx.doi.org/10.15359/ree.19-2.23

URL: http://www.una.ac.cr/educare

CORREO: educare@una.cr

Tabla 2

Opiniones estudiantiles acerca de los elementos del entorno institucional que favorecieron el desarrollo de su aprendizaje en el marco de la práctica supervisada

\begin{tabular}{|c|c|c|c|c|}
\hline & Pedagogía I y II ciclo & Inglés & Preescolar & Educación Especial \\
\hline $\begin{array}{l}\text { Valoración } \\
\text { del entorno } \\
\text { institucional }\end{array}$ & $\begin{array}{l}\text { - El elemento que más } \\
\text { me ayudó fue que yo } \\
\text { escogí una escuela rural } \\
\text { donde los padres, niños } \\
\text { y la escuela me ayudó, yo } \\
\text { organizo las reuniones, } \\
\text { visitas al hogar, el director } \\
\text { me dice niña y eso ayudó. } \\
\text { Pero hay problemas de } \\
\text { infraestructura y falta de } \\
\text { recursos. Apertura con los } \\
\text { padres de familia. } \\
\text { - Es determinante el lugar. } \\
\text { - Los recursos de la escuela } \\
\text { (laboratorio de cómputo, } \\
\text { proyector multimedia, } \\
\text { biblioteca) los llevé a la } \\
\text { Biblioteca para ver los } \\
\text { videos, solo un profesor } \\
\text { y yo los utilizamos. } \\
\text { Hay plaza, baños bien } \\
\text { equipados. } \\
\text { - Si se dispone del material } \\
\text { y recurso necesarios para } \\
\text { desarrollar la práctica. }\end{array}$ & $\begin{array}{l}\text { - A mí me ayudó que no } \\
\text { hay aula de inglés hay } \\
\text { que estar pasándose de } \\
\text { aula, tiene menos de } 40 \\
\text { minutos para dar la clase } \\
\text { y eso le ayuda a controlar } \\
\text { el tiempo, escoger } \\
\text { actividades que uno } \\
\text { planea. } \\
\text { - Al planeamiento no se le } \\
\text { da seguimiento. }\end{array}$ & $\begin{array}{l}\text { - Yo estoy en un lugar } \\
\text { sumamente marginado, } \\
\text { pobre, violento y molesto, } \\
\text { con una maestra mayor, } \\
\text { ella es alejada de los } \\
\text { niños, al llegar yo tan } \\
\text { cariñosa los niños y } \\
\text { padres hicieron a un } \\
\text { lado a la maestra y me } \\
\text { tomaron más en cuenta a } \\
\text { mí incluso me pedían cita. } \\
\text { El ser más humana con los } \\
\text { niños hizo un clic. } \\
\text { - El kínder tenía demasiado } \\
\text { material y eso fue lo mejor } \\
\text { del mundo, se podían } \\
\text { hacer actividades variadas } \\
\text { y me dejaban usarlo. } \\
\text { - Es increíble la cantidad } \\
\text { de chismes y la magnitud } \\
\text { de los mismos. Habíamos } \\
\text { varias haciendo la práctica } \\
\text { en la misma institución } \\
\text { y nos comparaban en lo } \\
\text { que traíamos o hacíamos. } \\
\text { Rivalidad entre colegas } \\
\text { practicantes. } \\
\text { - Otras docentes valoraban } \\
\text { el trabajo. } \\
\text { - Poca oportunidad de } \\
\text { escoger. }\end{array}$ & $\begin{array}{l}\text { - Tuve estudiantes con } \\
\text { mucho compromiso } \\
\text { cognitivo. Yo hice la } \\
\text { práctica en un centro } \\
\text { donde se carece de } \\
\text { material, no había con } \\
\text { qué hacer masajes, yo no } \\
\text { podía comprar material, } \\
\text { pero el personal me } \\
\text { incorporó no como } \\
\text { estudiante sino como } \\
\text { una docente más en los } \\
\text { actos y actividades y } \\
\text { eso fue positivo para el } \\
\text { proceso. } \\
\text { - Tenía diversidad de niños } \\
\text { que atender, lo que me } \\
\text { costó. } \\
\text { - Hay maestros que } \\
\text { hacen mucho y otros } \\
\text { no, algunos llevaban } \\
\text { actividades o material } \\
\text { que se aplicara a la } \\
\text { mayoría, se turnaban y } \\
\text { compartían materiales. } \\
\text { - Mucha apertura del } \\
\text { ambiente institucional. } \\
\text { - No hay una percepción } \\
\text { profesional de las } \\
\text { estudiantes. }\end{array}$ \\
\hline
\end{tabular}

Los datos que aporta la tabla 2 dejan ver las valoraciones estudiantiles acerca de los aspectos del entorno institucional que a su criterio influyeron en el desarrollo de la práctica supervisada. Señalan, como elementos positivos, poder seleccionar la institución en la que iban a realizar su práctica supervisada, tener apoyo de los padres y madres de familia, y del personal docente anfitrión, y destacan el hecho de que algunas instituciones pongan a su disposición material para usar en las aulas. 
doi: http://dx.doi.org/10.15359/ree.19-2.23

URL: http://www.una.ac.cr/educare

CORREO: educare@una.cr

No obstante lo dicho, el estudiantado menciona otros aspectos del entorno que a su criterio no favorecen la práctica supervisada y entre ellos destacan: el que algunas de las personas docentes no apoyen ni les visualicen como personas profesionales. El tener poca oportunidad para escoger la institución o la persona anfitriona se constituye en un factor negativo desde la visión estudiantil. Mencionan, también, que sienten que no se les da seguimiento a sus planeamientos durante el proceso de práctica supervisada, aspecto que ha de ser atendido, pues, en la medida en que se sientan con más seguridad de lo que hacen, el factor emocional no intervendrá de manera negativa en sus desempeños.

La composición de los grupos de práctica es un factor negativo para el estudiantado de la carrera de Educación Especial, pues al no estar muy avanzadas en su carrera no se sienten en capacidad de lidiar con personas que requieren de mayor apoyo y algunas veces en servicios que no son muy conocidos para ellas. Este, a nuestro criterio, es un aspecto que debe ser atendido dentro de la carrera específica.

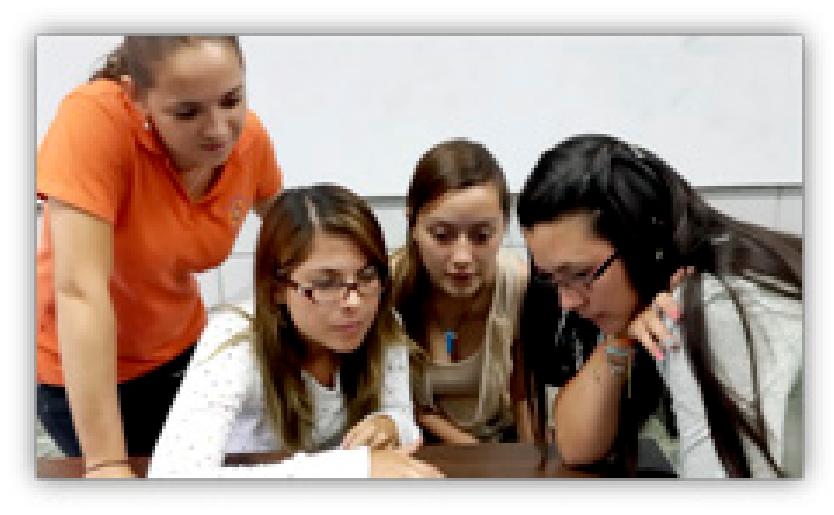

Figura 10. Como en todo proceso formativo, intervienen, durante la práctica supervisada, una serie de factores que incide y condiciona el desarrollo y evolución de cada estudiante en el escenario áulico, lo cual hace que se transforme en procesos altamente complejos. 
doi: http://dx.doi.org/10.15359/ree.19-2.23

URL: http://www.una.ac.cr/educare

CORREO: educare@una.cr

Tabla 3

Opiniones estudiantiles acerca de los mayores aportes que le brindó el realizar la práctica

\begin{tabular}{|c|c|c|c|c|}
\hline & Pedagogía I y II ciclo & Inglés & Preescolar & Educación Especial \\
\hline $\begin{array}{l}\text { Opiniones } \\
\text { estudiantiles }\end{array}$ & 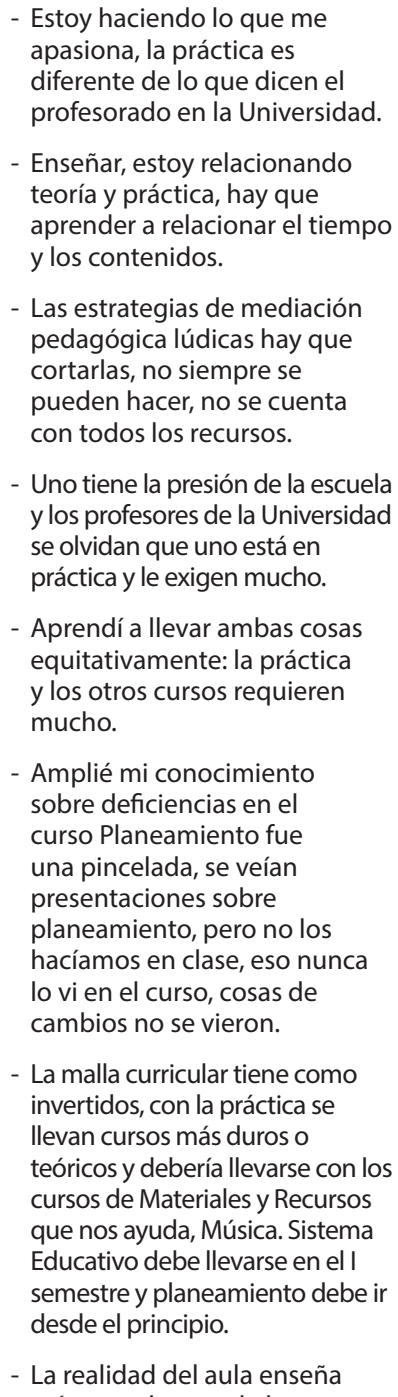 & 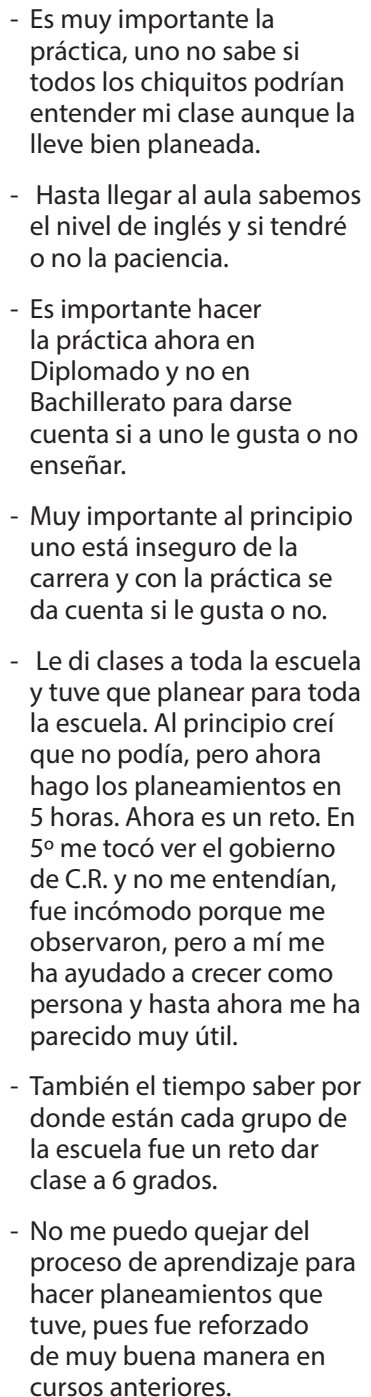 & $\begin{array}{l}\text { - Apoyo de la docente, } \\
\text { crecí como persona } \\
\text { y profesional. Mi } \\
\text { dominio en mi clase } \\
\text { es cada vez mejor. } \\
\text { - Apoyo de la tutora. }\end{array}$ & 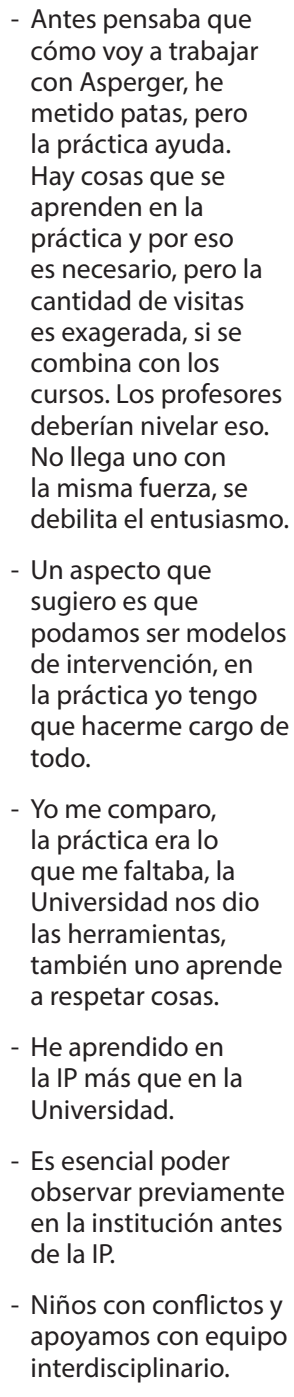 \\
\hline
\end{tabular}


doi: http://dx.doi.org/10.15359/ree.19-2.23

URL: http://www.una.ac.cr/educare

CORREO: educare@una.cr

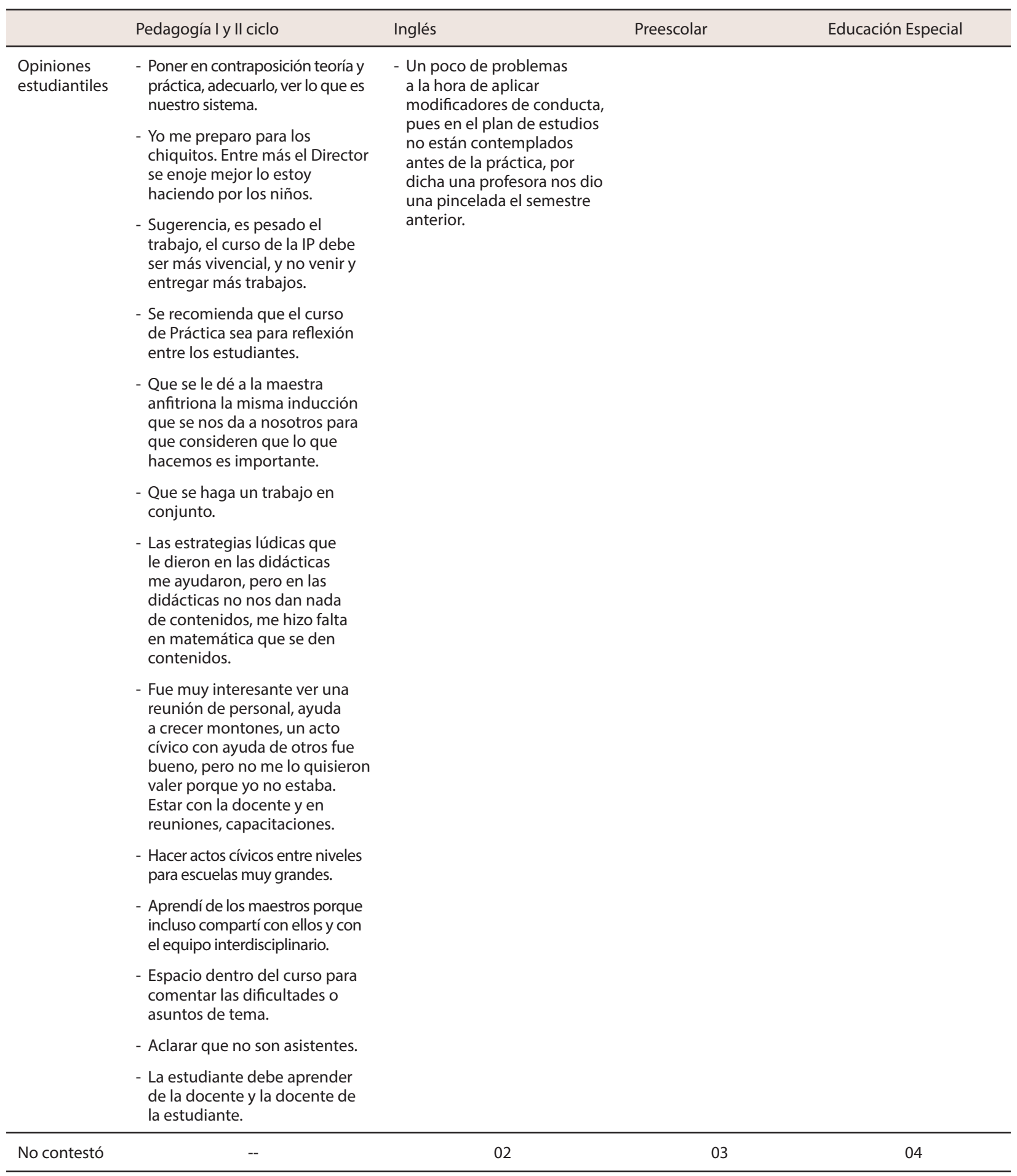


La tabla 3 permite rescatar las principales opiniones estudiantiles acerca de su proceso de práctica supervisada y los aportes que esta le ha otorgado. Es importante destacar que las valoraciones son primordialmente positivas, así, por ejemplo, se señala la oportunidad que les brinda esta experiencia para valorar si realmente la carrera en pedagogía es su opción para graduarse; señalan, además, que les permite relacionar la teoría y la práctica en contextos naturales, que pueden darse cuenta de la importancia del manejo del tiempo y de los contenidos y el enfrentarse al manejo disciplinar en los grupos.

Es interesante el señalamiento estudiantil en el sentido de que durante la práctica supervisada han aprendido más que en la Universidad, destacan aspectos que durante el proceso han podido visualizar como necesarios de corregir en el proceso formativo.

A partir de los datos, los elementos que requieren análisis al interior de las carreras nos parece que serían los siguientes:

- Valorar la estructura de la malla curricular, ya que a criterio estudiantil, coinciden con la práctica supervisada cursos que ellos consideran como muy pesados, o al menos en los cuales se les exige mucho.

- Señalan que las didácticas enfatizan en estrategias lo cual es valioso, pero que ya en la práctica sienten la necesidad de que en dichos cursos se haga estudio de los contenidos específicos que deberán trabajar en las instituciones o espacios pedagógicos alternativos.

- Indican también que los cursos de planeamiento no enfatizan en la elaboración y sienten que esto debe corregirse, pues es la base del trabajo durante la práctica supervisada.

- De igual manera, señalan que antes de realizar la práctica supervisada deberían de llevar los cursos sobre manejo de límites y de conducta, pues son necesarios para la experiencia de práctica.

\section{Principales fortalezas de la práctica supervisada, desde la perspectiva del estudiantado}

Al estudiantado que vivenció el proceso de práctica supervisada le fue solicitado que definiera, por orden de importancia, las tres principales fortalezas que, a su criterio, habían identificado en el proceso desarrollado. A continuación, se describen los hallazgos en cuanto a la principal fortaleza desde la visión del estudiantado, en primer lugar por carrera, seguido de una visión global. 
doi: http://dx.doi.org/10.15359/ree.19-2.23

URL: http://www.una.ac.cr/educare

CORREO: educare@una.cr

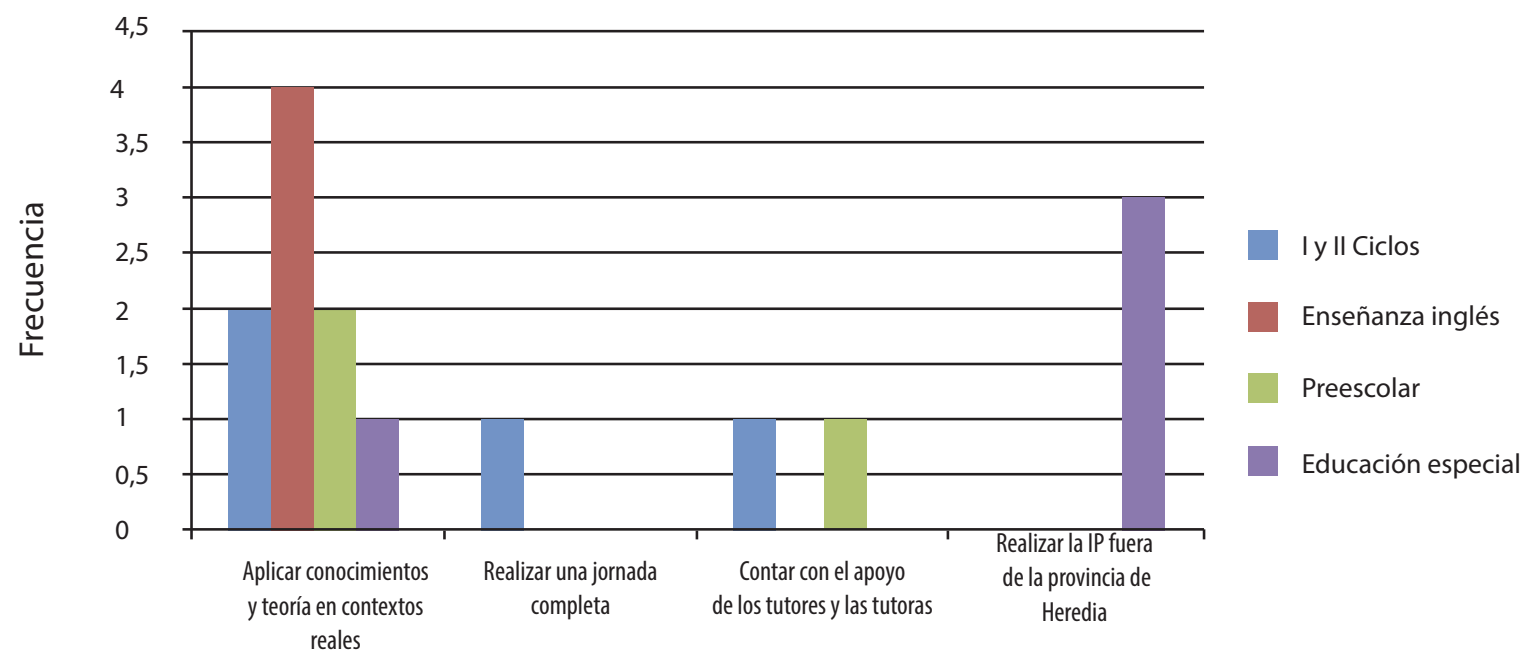

Fortaleza identificada por carrera

Figura 11. Principal fortaleza de la práctica supervisada, desde la perspectiva del estudiantado, según carrera que cursa.

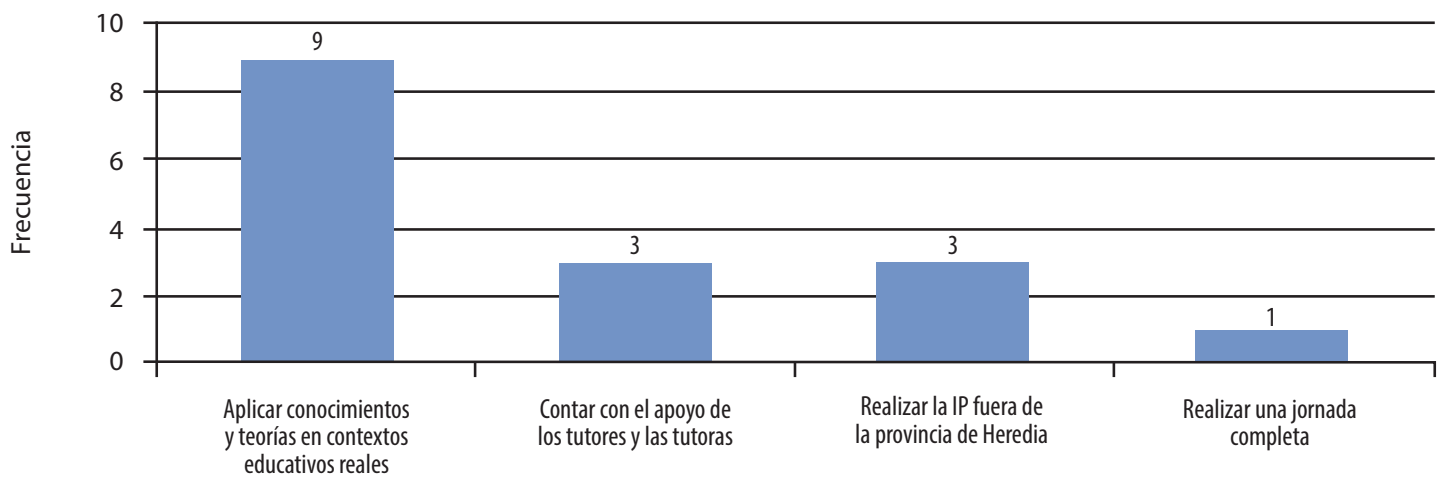

Fortalezas identificadas por el estudiantado

Figura 12. Visión general del estudiantado, acerca de la principal fortaleza de la práctica supervisada, según frecuencia. 
doi: http://dx.doi.org/10.15359/ree.19-2.23

URL: http://www.una.ac.cr/educare

Las figuras 11 y 12 permiten resumir la perspectiva estudiantil, acerca de la principal fortaleza de la práctica supervisada, según la carrera que cursa y según una perspectiva global. En un análisis por carrera, es interesante señalar que como principal fortaleza, el alumnado de I y II Ciclos menciona en primer lugar de importancia, la aplicación de conocimientos y teorías vistas en el ámbito universitario en contextos educativos reales que les preparan para su futura función como docentes, con frases como: "La IP [entendida como práctica supervisada] permite poner en práctica el conocimiento adquirido y comprobar que realmente estamos haciendo lo que nos apasiona y que estamos capacitados para desempeñar la labor educativa". De igual manera comentaron como fortaleza la posibilidad de realizar la práctica supervisada en jornadas completas y contar con el apoyo tutorial.

Por otra parte, el estudiantado de Enseñanza del Inglés en I y II ciclos, menciona en su totalidad como principal fortaleza de la práctica supervisada, que logran aplicar sus conocimientos y teorías en realidades educativas como expresiones como "Nos ayuda a reconocer y vivir en contexto real de una escuela". El estudiantado de la carrera de Educación Preescolar, por su parte, señaló como principal fortaleza de la práctica supervisada, el poder aplicar conocimientos y teorías en realidades educativas concretas, indicando la importancia de la práctica y la experiencia "práctica (experiencia)", así como contar con el apoyo del personal de tutoría.

Es interesante mencionar que el estudiantado participante, de la carrera de Educación Especial, en su totalidad, menciona que la principal fortaleza de la práctica supervisada fue la posibilidad de "realizar su proceso en instituciones fuera de la provincia de Heredia", cabe señalar que algunas estudiantes viven en zonas alejadas y esa posibilidad les ha sido muy beneficiosa según sus criterios: "La posibilidad de realizar la IP [entendida como práctica supervisada], en la provincia de Cartago", "La accesibilidad a centros de fuera de la provincia de Heredia".

En el sentido señalado anteriormente, donde las personas estudiantes de Educación Especial valoran el que exista apertura para la escogencia de los lugares para la realización de la práctica supervisada, hay una divergencia con el grupo del personal observador de la carrera de Preescolar quienes manifiestan que al estudiantado de esa carrera no hay que brindarles apertura, sino circunscribir sus prácticas a ciertas provincias.

De manera global, es posible señalar que el estudiantado menciona como principal fortaleza de la práctica supervisada aspectos referidos a la aplicación de conocimientos y teorías en contextos educativos reales (09 estudiantes), contar con el apoyo del personal tutor (03 estudiantes), poder realizar la práctica supervisada fuera de la provincia de Heredia (03 estudiantes) y hacerlo en una jornada completa (01 estudiante). 


\section{Percepción estudiantil en torno a aspectos de la práctica supervisada que requieren ser mejorados}

Al estudiantado participante en la investigación, se le solicitó que expresara, en orden de importancia, tres aspectos sobre la práctica supervisada, que a su criterio debían ser mejorados. A continuación, siguiendo el orden de importancia expresado por el estudiantado se destacan los hallazgos prioritarios

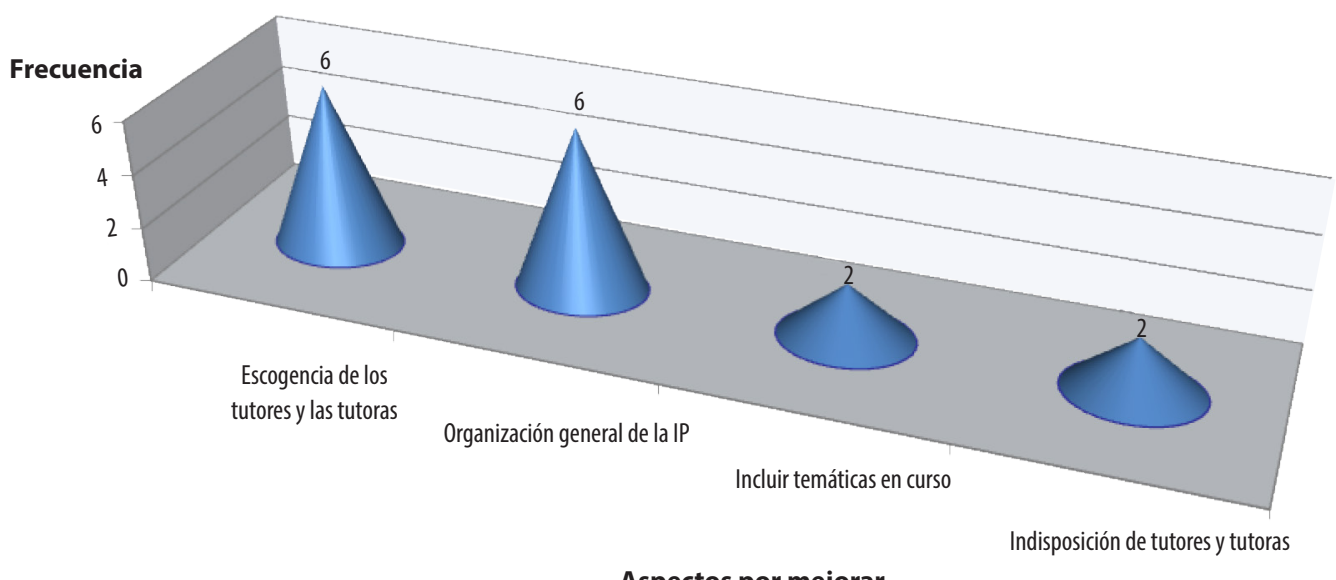

Figura 13. Principal aspecto que a criterio estudiantil ha de ser mejorado en la práctica supervisada.

La figura 13 destaca los principales aspectos que, a criterio del estudiantado que realizó la práctica supervisada durante el 2012, han de ser mejorados en dicho proceso. Es interesante destacar que en las cuatro carreras, el estudiantado destaca como primeros aspectos importantes de mejorar: la escogencia del personal docente-tutor, la organización general de la práctica supervisada, la inclusión de temáticas en los cursos, y la indisposición del profesorado observador hacia ciertas situaciones propias de la práctica supervisada, como reposición de visitas, entre otros. A continuación se detalla cada uno de esas categorías de análisis.

La primera categoría mencionada por el estudiantado se refiere al hecho de que se contraten "Profesores observadores o tutores graduados de la UNA o que conozcan perfectamente el proceso de formación que hemos tenido", "con respecto a los observadores me parece que deberían ser profesionales comprometidos con el proceso". 
Seguidamente se menciona la necesidad de mejorar la organización de la práctica supervisada, básicamente, el estudiantado menciona aspectos referidos a "Muchas visitas durante la IP [entendida como práctica supervisada]".

En orden descendente el estudiantado advierte como aspecto prioritario de ser atendido; "Ia "inclusión de un curso de NEE y un taller de modificación de conducta antes de la realización de la IP", "Recibir un curso que nos ayude a manejar ciertas circunstancias que suceden en el aula, ya que todos los cursos es más que todo de teoría", y mencionan también, la necesidad de "mejorar el orden de las materias anteriores a la IP".

Otro aspecto que, a criterio estudiantil, requiere ser mejorado en la práctica supervisada es la indisposición del personal docente-tutor para "reponer visitas cuando el motivo de suspensión ha sido ajeno al estudiante", así como la indisposición mostrada para "realizar visitas fuera de Heredia".

\section{Conclusiones y recomendaciones sobre la valoración de la práctica supervisada, desde la visión estudiantil}

Se presentan a continuación las conclusiones y recomendaciones más relevantes, para lo cual se asumen las principales categorías de análisis utilizadas con el propósito de concretar la información recopilada.

\section{Papel de la maestra anfitriona}

- Destacan positivamente el hecho de que algunas personas docentes les dejaron trabajar con libertad y sintieron su apoyo.

- Mencionan aspectos negativos referidos al hecho de que el profesorado anfitrión suele ser asignado por la persona directora de las instituciones y señalan que muchas veces se les dificulta el trabajo con el grupo, pues el personal docente suele poner las reglas, límites y manejar la disciplina del grupo, lo cual entorpece su labor como persona estudiante-practicante.

- Como aspecto crítico, el estudiantado señala, por ejemplo, que en muchas ocasiones las docentes del personal anfitrión se han plegado a un sistema educativo pasivo, dejando de lado aspectos que consideran medulares como la creatividad, la diversidad de estrategias, entre otros. 
doi: http://dx.doi.org/10.15359/ree.19-2.23

URL: http://www.una.ac.cr/educare

CORREO: educare@una.cr

\section{Impacto del entorno institucional}

- El estudiantado considera un acierto el tener la oportunidad de seleccionar la institución en la que realizarían su práctica supervisada.

- Consideran valioso el tener apoyo de los padres y madres de familia, del personal docente anfitrión y destacan el hecho de que algunas instituciones pongan a su disposición material para usar en las aulas.

- En el sentido señalado, destacan como negativo los aspectos mencionados, tales como no tener la oportunidad de escoger la persona anfitriona, sino que en muchos casos fue impuesta por el director o la directora de la institución. Agregan que algunas de las personas docentes anfitrionas no las respetan ni apoyan.

\section{Aprendizajes y logros del proceso de práctica supervisada}

Es importante destacar que las valoraciones son primordialmente positivas, así por ejemplo, se señala la oportunidad que les brinda esta experiencia para valorar, si realmente la carrera en pedagogía es su opción para graduarse; señalan, además, que les permite relacionar la teoría y la práctica en contextos naturales, que pueden darse cuenta de la importancia del manejo del tiempo y de los contenidos y el enfrentarse al manejo disciplinar en los grupos.

\section{Principales fortalezas de la práctica supervisada}

- Como principal fortaleza el estudiantado de I y II Ciclos menciona, en primer lugar de importancia, la aplicación de conocimientos y teorías vistas en el ámbito universitario en contextos educativos reales que les preparan para su futura función como docentes. De igual manera, comentaron como fortaleza la posibilidad de realizar la práctica supervisada en jornadas completas y contar con el apoyo de las personas tutoras.

- El estudiantado de Enseñanza del Inglés en I y II ciclos, y de Educación Preescolar menciona como principal fortaleza de la práctica supervisada que logran aplicar sus conocimientos y teorías en realidades educativas.

- El estudiantado de la carrera de Educación Especial, en su totalidad, menciona que la principal fortaleza de la práctica supervisada ha sido la posibilidad de "realizar su proceso en instituciones fuera de la provincia de Heredia", cabe señalar que muchas estudiantes residen en zonas alejadas a la sede universitaria y durante el proceso de práctica se encarece el tener que viajar lejos de sus lugares de residencia. 
- Como segunda y tercera fortaleza de la práctica supervisada, el estudiantado participante manifiesta, de forma reiterada, que esta ha sido positiva, destacando la importancia de aspectos propios de los aprendizajes que obtienen en las instituciones donde se insertan, del profesorado a cargo y del apoyo recibido en dicho proceso (figura 14).

\section{Aspectos de la práctica supervisada que requieren ser mejorados}

- Es interesante destacar que en las cuatro carreras, el estudiantado destaca como primeros aspectos importantes de mejorar: la escogencia de las personas tutoras, la organización general de la práctica supervisada, la inclusión de temáticas en los cursos que le ayuden en el manejo de la disciplina y los contenidos, y la indisposición de las personas tutoras-observadoras hacia ciertas situaciones propias de la práctica supervisada como reponer visitas que han sido canceladas por actividades de la institución sin que medie responsabilidad estudiantil.

- Hay un señalamiento importante del estudiantado acerca de que se valore de manera adecuada la escogencia de las instituciones o espacios en los que se realizará la práctica supervisada, así como las horas asignadas de práctica, dependiendo del servicio.

- Señala el estudiantado la necesidad de que el profesorado observador sea personas bien preparadas para ello. De igual manera, añaden que debe existir mayor coordinación entre el personal docentes que coordina el curso de práctica y el personal docente observador.

- Otro aspecto por mejorar es que se pueda tener un acercamiento con las instituciones educativas, de modo que el estudiantado pueda elegir a la persona docente con la que desea trabajar y que esta no sea impuesta institucionalmente.

- Solicitan una mejor organización de los requerimientos de los cursos paralelos al proceso de práctica supervisada, el uso del tiempo, así como la necesidad de abrir distintos sitios para la realización de la práctica.

- Se menciona como aspecto importante también, la necesidad de que el proceso de observación de la práctica sea realmente de "acompañamiento" y no se priorice como un "proceso evaluativo". 
doi: http://dx.doi.org/10.15359/ree.19-2.23

URL: http://www.una.ac.cr/educare

CORREO: educare@una.cr

\section{Recomendaciones a la dirección de la DEB y a los académicos y académicas de las distintas carreras, desde la visión del estudiantado}

- Valorar la estructura de la malla curricular, ya que a criterio estudiantil, coinciden con la práctica supervisada cursos que ellos consideran como muy pesados, o al menos en los cuales se les exige mucho.

- Señalan que las didácticas enfatizan en estrategias lo cual es valioso, pero que ya en la práctica sienten la necesidad de que en dichos cursos se haga estudio de los contenidos específicos que ellos y ellas deberán trabajar en las instituciones o espacios emergentes.

- Indican también que los cursos de planeamiento no enfatizan en la elaboración de estos y sienten que tal situación debe corregirse, pues es la base del trabajo durante la práctica supervisada.

- De igual manera, señalan que antes de realizar la práctica supervisada deberían llevar los cursos sobre manejo de límites y de conducta, pues son necesarios para la experiencia de práctica.

- Hay un señalamiento importante del estudiantado acerca de que se valore de manera adecuada la escogencia de las instituciones o espacios en los que se realizarán la experiencia, así como las horas asignadas de práctica dependiendo del servicio.

- Parte del estudiantado manifiesta que, durante la práctica supervisada, realmente no se da un proceso de acompañamiento del equipo docente observador, lo cual provoca que este sea un proceso en su mayor parte de orden evaluativo.

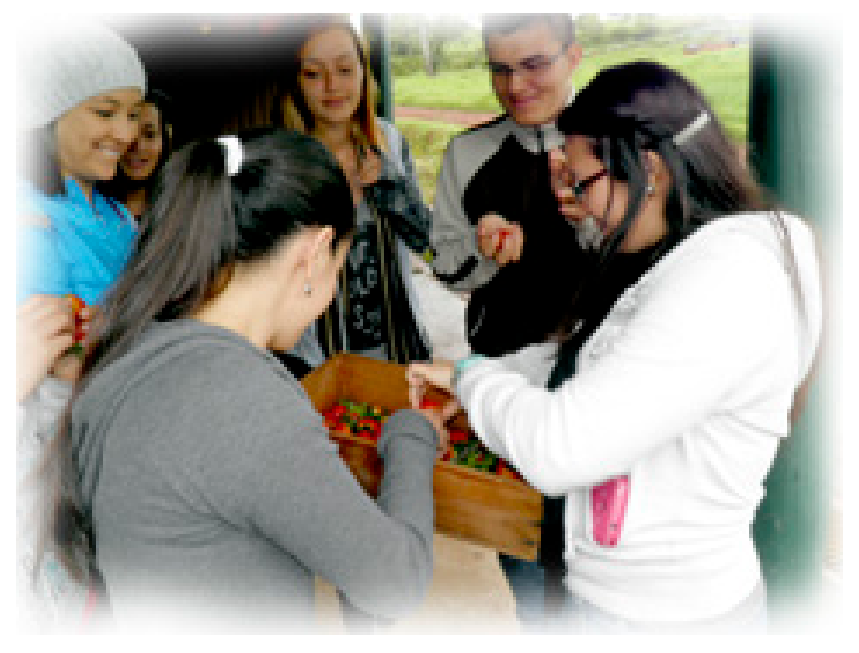

Figura 14. Durante la formación del estudiantado se propone una práctica reflexiva, que implica valorar, por su parte, su propia experiencia a partir de la realidad. 
Ha sido valioso, para el proceso investigativo llevado a cabo, el haber contado con las miradas estudiantiles acerca de la experiencias en su práctica supervisada, así como con la participación de docentes observadores y profesores de curso. Contar con esa mirada del estudiantado aporta elementos importantes para la toma de decisiones e, incluso, para profundizar en el análisis de los lineamientos o procedimientos que a nivel universitario se siguen para la realización de experiencias prácticas en instituciones educativas o en espacios emergentes. Gracias a todos por sus significativos aportes.

\section{Referencias}

Alliaud, A. y Antelo, E. (2009). Los gajes del oficio. Buenos Aires: Aique.

Babbie, E. (2000). Fundamentos de la investigación social. México, D.F.: Internacional Thomson Editores.

Badilla, I., Ramírez, A., Rizo, L. y Rojas, K. (2013). La praxis profesional del docente en formación y del formador de formadores (050918). Manuscrito inédito. Universidad Nacional. División de Educación Básica.

Bejarano, S., Dobles, C., León, H. y Quesada, E. (2006). Intervención pedagógica praxis desde la formación universitaria (Informe final de proyecto 050309). Manuscrito inédito. Universidad Nacional. División de Educación Básica.

Bejarano, S., Dobles, C., León, H., Quesada, E., Rojas, D. y Vásquez, E. (2007). Políticas y lineamientos que orientan el desarrollo y ejecución de la intervención pedagógica. Manuscrito inédito. Universidad Nacional. División de Educación Básica.

Boggino, N. y Rosekrans, K. (2007). Investigación-acción: Reflexión crítica sobre la práctica educativa. Orientaciones prácticas yexperiencias. Sevilla: Absys Biba.

Bruns, B. y Luque, J. (2014). Profesores excelentes. Docentes excelentes: Cómo mejorar el aprendizaje en América Latina y el Caribe [resumen]. Washington, DC: Banco Mundial. Recuperado de http:// www.bancomundial.org/content/dam/Worldbank/Highlights\%20\&\%20Features/lac/LC5/ Spanish-excellent-teachers-report.pdf

Camacho, M. y Rojas, K. (Setiembre-diciembre, 2013). La mirada de las profesoras coordinadoras de la intervención pedagógica en la carrera de Pedagogía con Énfasis en I y ll Ciclo. Revista Electrónica Educare, 17(3), 315-337. Recuperado de http://www.revistas.una.ac.cr/index.php/EDUCARE/ article/view/5252

Camacho, M., Castillo, R., León, H., Miranda, A., Pereira, Z. y Vásquez, E. (2012). Disposiciones generales paralaintervención pedagógica. Manuscrito inédito. Universidad Nacional, División de Educación Básica. 
doi: http://dx.doi.org/10.15359/ree.19-2.23

URL: http://www.una.ac.cr/educare

CORREO: educare@una.cr

Camacho, M., Castillo, R., León, H., Miranda, A., Pereira, Z. y Vásquez, E. (2014). Informe final de autoevaluación. Valoración del proceso de práctica supervisada en las carreras de la División de Educación Básica a nivel de diplomado y en el bachillerato en educación especial, desde la visión de estudiantes profesores y observadores. Manuscrito inédito. Universidad Nacional, División de Educación Básica.

Chaves, A. L., Rizo L. y Vindas, M. (2010). Experiencias del curso "Intervención pedagógica en la educación preescolar": La visión de las académicas, docentes y estudiantes. Revista Electrónica Educare, 14 (Extraordinario), 79-95. Recuperado de http://www.redalyc.org/ articulo.oa?id=194115343007

Correa, E. (2011). La práctica docente: Una oportunidad de desarrollo profesional. Perspectiva educacional, 50(2), 77-95. Recuperado de http://www.perspectivaeducacional.cl/index. php/peducacional/article/viewFile/41/21

Escobar, N. (2007). La práctica profesional docente desde la perspectivas de los estudiantes practicantes. Acción pedagógica, 16, 182-193. Recuperado de http://www.ciegc.org.ve/ contenido/documents/Articulo\%20Nancy.pdf

Flores, L. E. y Pereira, Z. (1991). Aspectos metodológicos de la evaluación del proceso de práctica supervisada de alumnos de la carrera de Ciencias de la Educación con énfasis en I y II ciclos, modalidad presencial, según criterio de maestros y directores. Experiencia 19871988. Revista C.I.D.E., 7, 17-21.

Gamboa, A. (1997). Evaluación de intervención pedagógica de 1987 a 1996. Manuscrito inédito Universidad Nacional. División de Educación Básica.

Herrera, A., Quesada, E. y Rizo, L. (2008). Intervención pedagógica: Praxis desde la formación universitaria (020312). Manuscrito inédito. Universidad Nacional. División de Educación Básica.

Miranda, A. (2011). Informe del proceso de práctica supervisada desarrollado en la carrera de I y II Ciclos. Manuscrito inédito. Universidad Nacional. División de Educación Básica.

Pereira, Z. (2010). La mirada de estudiantes de la Universidad Nacional hacia el docente y la docente: Sus características y clima de aula (Tesis de doctorado). Universidad Estatal a Distancia. San José, Costa Rica.

Pulido, A. (1992). Estadística y técnicas de investigación social (9a ed.). Madrid: Pirámide.

Quesada, E. J. (Mayo-agosto, 2013). La intervención pedagógica como un reto de la formación universitaria: Hacia una práctica profesional articulada. Revista Electrónica Educare, 17(2), 167-182. Recuperado de http://www.revistas.una.ac.cr/index.php/EDUCARE/article/ view/5037/4823 
doi: http://dx.doi.org/10.15359/ree.19-2.23

URL: http://www.una.ac.cr/educare

Sanjurjo, L. O. (2002). La formación práctica de los docentes. Reflexión y acción en el aula. Rosario: Homo Sapiens.

Sanjurjo, L. O. (Coord.). (2009). Los dispositivos para la formación en las prácticas profesionales. Rosario: Homo Sapiens.

Terigi, F. (Septiembre-diciembre, 2009). La formación inicial de profesores de educación secundaria: Necesidades de mejora, reconocimiento de sus límites. Revista de Educación, 350, 123-144. Recuperado de http://www.revistaeducacion.educacion.es/ re350/re350 06.pdf

Villegas-Reimers, E. y Ávalos, B. (2003). Dos experiencias en formación docente: EUA y Chile. (Serie Cuadernos de discusión 2). México: Secretaría de Educación Pública. Recuperado de http://basica.sep.gob.mx/fcms/cds02.pdf

\section{(O) Cómo citar este artículo en APA:}

Camacho-Oviedo, M., Castillo-Cedeño, R., León-Arce, H., Miranda-Calderón, L. A. y Pereira-Pérez, Z. (Mayoagosto, 2015). La mirada estudiantil acerca del proceso de práctica supervisada en las carreras de Pedagogía de la Universidad Nacional. Revista Electrónica Educare, 19(2), 429-465. doi: http://dx.doi. org/10.15359/ree.19-2.23

Nota: Para citar este artículo en otros sistemas puede consultar el hipervínculo "Como citar el artículo" en la barra derecha de nuestro sitio web: http://www.revistas.una.ac.cr/index.php/EDUCARE/index 